\title{
Cash Flow, Consumption Risk and Cross Section of Stock Returns
}

\author{
Zhi Da*
}

First draft: Sep 10, 2004

This version: Jan 8, 2006

ABSTRACT

This paper directly links the risk premium on an asset to two characteristics of its underlying cash flow: cash flow covariance with aggregate consumption; and cash flow duration, which measures the temporal pattern of the cash flow. Their impact on the cross-sectional variation of risk premia can be largely captured by a two-factor cash flow model. While cash flow covariance is of firstorder importance in explaining the cross-sectional variation of risk premia, cash flow duration still provides additional explanatory power through a second-order interaction term. Cash flow duration is particularly important in explaining the value premium given as value and growth stocks have significantly different durations. Empirically, I measure both cash flow characteristics using only consumption and accounting data. I show that the two-factor cash flow model is able to explain $82 \%$ of the cross-sectional variation in returns on size or book-to-market sorted stock portfolios.

${ }^{*}$ Kellogg School of Management, Northwestern University, 2001 Sheridan Rd, Evanston IL 60208. E-mail: zda@kellogg.northwestern.edu. I wish to thank Ravi Jagannathan for his continuing guidance and support. I also received helpful comments and suggestions from Torben Andersen, Ravi Bansal, Kent Daniel, Martin Eichenbaum, Paul Gao, Robert Korajczyk, Arvind Krishnamurthy, Deborah Lucas, Christian Lundblad, Robert McDonald, Christopher Polk, Ernst Schaumburg, George Skoulakis and Yong Wang. I am responsible for any errors or omissions. 


\section{Introduction}

A key insight in financial economics is that differences in the expected return across assets are determined by the differences in asset's exposure to systematic risk. For example, in the standard consumption-based asset pricing model (CCAPM, c.f. Rubinstein 1976, Lucas 1978 and Breeden 1979), the expected return on an asset is determined by its consumption beta which measures the comovement between asset return and aggregate consumption. If the asset return comoves very little with the aggregate consumption, thus providing insurance to the investor against consumption fluctuation, then investor is willing to accept a lower expected return to hold the asset. In typical rational expectation asset pricing models, prices (and returns) are set by expectations about future cash flows. It is therefore worthwhile to look at asset pricing model representations that relate cash flow characteristics to risk premium since they seem integral to the efficacy of rational expectation asset pricing models .

An asset's cash flow has at least two important characteristics. The first characteristic is the degree of its comovement with consumption, which I label as cash flow covariance. In the consumption-based models of Abel (1999) and Bansal and Yaron (2004), degrees of such comovement ultimately determine the expected return on the stock. The empirical success of such cash flow comovement measure in explaining the cross-sectional variation in expected return has been demonstrated by Bansal, Dittmar and Lundblad (2005), who show that a cash flow beta, which measures such comovement, explains $62 \%$ of the cross-sectional variation in risk premia across various assets. Another important cash flow characteristic is the temporal pattern of cash flow. I label this characteristic as cash flow duration. ${ }^{1}$ Lettau and Wachter (2005) analyze an economy where different assets have the same cash flow covariance and only differ in their cash flow durations. In this economy, high cash flow duration leads to lower expected return. ${ }^{2}$ I show theoretically and empirically that both characteristics are needed to explain the cross-sectional variation in risk premia. Although cash flow covariance has a first-order impact on the cross-sectional variation of risk premia, ${ }^{3}$ the cash flow duration provides additional explanatory power through a secondorder interaction term. Its impact on the risk premium depends on the sign and magnitude of

\footnotetext{
${ }^{1}$ The definition of cash flow duration in this paper is different from the definition of duration in the fixed-income literature. However, the two definitions are likely to be monotonically related to each other as discussed in Appendix A3.3.

${ }^{2}$ The role of cash flow duration has been highlighted in the literature. Early literature such as Jagannathan and Viswanathan (1988) and Connor and Korajczyk (1989) demonstrate that the replication of a stock's cash flows in a dynamic world requires bonds; therefore, bond factors contribute to the correct pricing of equities. Cornell, using a case study (1999) and regression analysis (2000), reemphasizes the importance of equity duration risk in determining firm's cost of capital. More recently, Dechow, Sloan and Soliman (2004) analyze the equity duration risk empirically in a cross-section and show that stocks with higher equity duration risk earn lower returns.

${ }^{3}$ The recent paper of Santos ad Veronesi (2005) also shows that the cross-sectional differences in fundamental cash flow risk (covariance of individual asset's cash flow with the aggregate economy) generate the value premium (stocks with high book-to-market ratios earn higher average returns).
} 
the cash flow covariance. In explaining the return difference of two assets with very different cash flow durations (such as value and growth stock portfolios), it is therefore important to account for cash flow duration. Empirically, I show that a two-factor cash flow model incorporating both cash flow characteristics is able to explain $82 \%$ of the cross-sectional variation in risk premia in 20 size or book-to-market sorted stock portfolios. In addition, the two-factor cash flow model compares favorably against common benchmark models.

I capture both cash flow characteristics, by assuming that an asset's cash flow as a share of aggregate consumption is mean-reverting, and can thus be modeled as an AR(1) process. Once modeled as such, I can then define the cash flow covariance as the contemporaneous covariance between (1) innovations in cash flow share and (2) innovations in aggregate consumption growth, a covariance assumed constant through time. I define the cash flow duration as the discrepancy between the current cash flow share and its steady state value. These two characteristics are denoted as Cov and Dur, respectively. Arguably, the AR(1) assumption about cash flow share may not extend to individual stock and certain sector portfolios. However, I show that it is a reasonable assumption for the cash flows in buy-and-hold stock portfolios constructed based on size or book-to-market ratio. ${ }^{4}$ I then focus on deriving and testing the implication of such cash flow process on the cross-sectional variation in expected returns. Under reasonable assumptions about investors' preferences and the stochastic process of aggregate consumption growth, I show that the price and expected (excess) return of the cash flow stream can be expressed using Cov and Dur. A large portion of the cross-sectional variation in average excess return can then be explained by the following two-factor cash flow model:

$$
\begin{aligned}
E\left[R_{t+1}^{i}-R f_{t}\right] & =\gamma_{0}+\gamma_{1} \operatorname{Cov}^{i}+\gamma_{2} \operatorname{Cov}^{i} \times \operatorname{Dur}_{t}^{i} \\
\gamma_{0}, \gamma_{1} & >0 \text { and } \gamma_{2}<0 .
\end{aligned}
$$

The above cash flow model works fairly intuitively. In a multi-period world, an asset is a portfolio of cash flow claims with different maturities. ${ }^{5}$ Its expected excess return is therefore the value-weighted average of the expected excess returns of all cash flow claims. Consider two cash flow claims with the same maturity: the one with higher Cov should earn higher return, much like the way a high beta stock should earn higher return. Hence, the positive $\gamma_{1}$. The impact of duration, on the other hand, is subtler. Recall that the cash flow share is mean-reverting by assumption, and so the impact of a high Cov diminishes with maturity. As maturity approaches infinity, the expected return of any cash flow claim converges to the expected return of a zero-Cov

\footnotetext{
${ }^{4}$ Similar AR(1) assumption about cash flow share has been used for industry portfolios as in Menzly, Santos and Veronesi (2004) and Santos and Veronesi (2004).

${ }^{5}$ In the case of a stock, these cash flow claims are also denoted as "equity strips".
} 
cash flow claim. As a result, if Cov is positive, then the expected excess return on the cash flow claim decreases with maturity. When this happens, high Dur assets will have lower returns since a long-maturity cash flow claim with lower return receives higher weight. The reverse logic holds for negative Cov. This explains the negative $\gamma_{2}$ and the fact that the second factor is an interaction term between Cov and Dur.

I estimate both Cov and Dur using only consumption data and accounting data on cash flows. This estimation method differs from those of previous studies in two important ways. ${ }^{6}$ First, in order to examine the cash flow duration of a portfolio, I need to keep track of its cash flow over time without changing its composition. This consideration introduces an extra dimension to my cash flow data: whenever I form a portfolio, I "buy and hold" it for 12 years. Second, cash flows are not measured using dividend data; rather, following Vuolteenaho (2002a and 2002b), I make use of the clean-surplus accounting identity to work with earnings data. The use of earning to measure cash flow is better for firms who do not pay dividends or maintain a stable dividend payout ratio in the near future. ${ }^{7}$

I find that, empirically, cash flow covariance and duration are likely to be inversely related at least for size or book-to-market sorted portfolios. The inverse relation between cash flow covariance and duration explains why high-duration stock may earn significant lower expected return than low-duration stock as documented in Dechow, Sloan and Soliman (2004). Stocks with high cash flow duration may earn lower expected return simply because they happen to have, at the same time, low cash flow covariance. To better understand the relative importance of the two cash flow characteristics in determining the expected return of an asset, I need to construct portfolios where the two characteristics are "orthogonalized." I find that stock portfolios with similar cash flow durations but different book-to-market ratios still earn different returns and the return difference can be explained by the difference in their cash flow covariances. This is consistent the two-factor cash flow model (1) where cash flow covariance has a first-order impact on the cross-sectional variation of risk premia and shows that cash flow duration alone does not explain value premium.

\section{Other related literature}

The examination of the "cash flow risk" of an asset has been an active research area recently. The related papers fall into two groups, depending on their focus. Papers in the first group focus on the time series implications of the "cash flow risk." For example, Bansal and Yaron (2004) consider a model in which: (1) investors care about long-run risk, (2) there is a persistent and predictable component in consumption growth, and (3) the economy-wide volatility is time-varying. They

\footnotetext{
${ }^{6}$ Examples of those studies are: Bansal, Dittmar and Lundblad (2002), Hansen, Heaton and Li (2005), Menzly, Santos and Veronesi (2004) and Santos and Veronesi (2004).

${ }^{7}$ The empirical difficulty of working with dividend data is also highlighted in a review article by Campbell (2000).
} 
show that such a model can explain many time-series properties of the financial markets. Menzly, Santos and Veronesi (2004) analyze the predictability of dividend growth and asset return in an economy, in which assets have mean-reverting cash flows and agents have log utility with external habit.

Papers in the second group focus on the cross-sectional implications of the "cash flow risk." For example, Brennan and Xia (2003) analyze in a theoretical framework an ICAPM where the two state variables are real interest rate and Sharpe ratio, and study the impact of different sources of risk on the pricing of an equity strip as its maturity varies. Santos and Veronesi (2004) decompose the CAPM beta into two parts: a discount beta and a cash-flow beta and examine which one dominates using cross-section return data. Santos and Veronesi (2005) extends Menzly, Santos and Veronesi (2004) to explain simultaneously the time series properties of the market portfolio and the value premium in the cross-section. Hansen, Heaton and Li (2005) analyze theoretically the risk-return trade-off between cash flow risk and long run return of a security. Cohen, Polk and Vuolteenaho (2005) empirically analyze a cash-flow-based CAPM beta computed as the covariance between portfolio and market cash flow and show it explains the difference in price levels. Finally, Bansal, Dittmar and Lundblad (2005) show that a cash flow beta measure alone explains $62 \%$ of the cross-sectional variation in risk premia across various assets. With the exception of Bansal, Dittmar and Lundblad (2005), few papers have empirically tested the cross-sectional implications of the "cash flow risk" in relation to aggregate consumption. This paper makes a contribution to this line of research by showing, both theoretically and empirically, that the temporal pattern of cash flow as measured by Dur has additional explanatory power for the cross-section of stock returns.

Most empirical studies of consumption risk analyze the consumption beta of an asset, which measures the covariance between the asset's return and consumption growth (see early work by Breeden, Gibbons and Litzenberger, 1989 and Hansen and Singleton, 1983 and more recent advancements by Daniel and Marshall, 2004, Parker and Julliard, 2005 and Jagannathan and Wang, 2005, among others). In this paper, I also draw the connection between the cash flow characteristics and the usual consumption beta (see Appendix 2).

The remainder of the paper will be organized as follows: Section II describes a consumptionbased asset pricing framework and a mean-reverting cash flow share structure; Section III discusses in detail the cross-sectional implication and the two-factor cash flow model; Section IV contains the results of empirical analysis; Section V briefly concludes the findings; Appendix 1 contains detailed proofs; Appendix 2 relates cash flow characteristics to return-based consumption risk measures; Appendix 3 works out the cross-sectional implication of the mean-reverting cash flow share in a specific economy and shows the two-factor cash flow model to still perform well even with the 
presence of time-varying volatility; Appendix 4 discusses various econometric issues encountered in the empirical analysis.

\section{Model Setup}

In this section, I discuss the assumptions on the aggregate consumption dynamics, the stochastic discount factor in the economy and the asset's cash flow structure. These assumptions will also determine the time-series proprieties the financial market and the term structure of interest rate in this economy. However, these are not the focuses of this paper. Instead, I will focus on their implications the cross-sectional dispersion of stock (excess) returns. In addition, I assume conditional homoscedasticity and joint lognormality. ${ }^{8}$ I do not model time-varying volatility, even though that has been helpful in justifying many time-series properties of asset market (for instance in Bansal and Yaron, 2004), and could be straightforwardly incorporated into this setup (demonstrated in Appendix 3.) For our purposes of explaining cross-sectional variation in average expected (excess) return, the impact of time-varying volatility is relatively small, as shown by calibration and simulation results in Appendix 3.

\section{A. Aggregate consumption}

Assumption 1: Following Hansen, Heaton and Li (2005): log consumption growth is a secondorder stationary process, and therefore under the Wold Theorem, it has an infinite MA representation:

$$
\Delta c_{t+1}=\mu_{c}+\phi^{c}(L) w_{t+1}
$$

where $w_{t}$ is iid standard normal random vector and $\phi^{c}(L)$ is the usual lag operator:

$$
\phi^{c}(z)=\sum_{j=0}^{\infty} \phi_{j}^{c} z^{j}
$$

where $\phi_{j}^{c}$ is a row vector and

$$
\sum_{j=0}^{\infty}\left|\phi_{j}^{c}\right|^{2}<\infty .
$$

Here, I bypass the underlying economic model, focusing only on the resulting statistical properties of equilibrium aggregate consumption process. The process nests many familiar structures

\footnotetext{
${ }^{8}$ I use notations consistent with previous research papers. Lower case is used to denote the log of the original variables.
} 
that have been imposed on the aggregate consumption growth. For instance:

- $\mathrm{AR}(1)$ in Mehra and Prescott (1985)

$$
\begin{aligned}
\Delta c_{t+1} & =\mu_{c}+\rho\left(\Delta c_{t}-\mu_{c}\right)+w_{t+1} \\
& \Leftrightarrow \phi^{c}(L)=(1-\rho L)^{-1} .
\end{aligned}
$$

- $\operatorname{ARMA}(1,1)$ in Bansal and Yaron (2002)

$$
\begin{aligned}
\Delta c_{t+1} & =\mu_{c}+\rho_{1}\left(\Delta c_{t}-\mu_{c}\right)+w_{t+1}-\rho_{2} w_{t} \\
& \Leftrightarrow \phi^{c}(L)=\left(1-\rho_{1} L\right)^{-1}\left(1-\rho_{2} L\right) .
\end{aligned}
$$

- VAR in Bansal and Yaron (2004)

$$
\begin{aligned}
\Delta c_{t+1} & =\mu_{c}+x_{t}+\sigma \eta_{t+1}, \\
x_{t+1} & =\rho x_{t}+\varphi_{e} \sigma e_{t+1}, \\
e_{t+1}, \eta_{t+1} & \sim N . i . i . d .(0,1) \\
& \Leftrightarrow \\
\phi^{c}(L) & =e 1^{\prime}(I-A L)^{-1} B \text { and } w_{t+1}=\left[\begin{array}{cc}
\eta_{t+1} & e_{t+1}
\end{array}\right]^{\prime}, \\
\text { where } e 1 & =\left[\begin{array}{ll}
1 & 0
\end{array}\right]^{\prime}, A=\left[\begin{array}{ll}
0 & 1 \\
0 & \rho
\end{array}\right], B=\left[\begin{array}{cc}
\sigma & 0 \\
0 & \varphi_{e} \sigma
\end{array}\right] .
\end{aligned}
$$

\section{B. Stochastic discount factor}

Assumption 2: Log stochastic discount factor (SDF) can be written (or approximated) as:

$$
m_{t+1}=\mu_{m}+\phi^{m}(L) w_{t+1} .
$$

Many preference specifications satisfy this assumption. For instance: ${ }^{9}$

\footnotetext{
${ }^{9} \gamma$ and $\psi$ denote coefficient of risk aversion and elasticity of intertemporal substitution respectively; $\delta$ is the time discount factor.
} 
- Power Utility:

$$
\mu_{m}=\log \delta-\gamma \mu_{c} \text { and } \phi^{m}(L)=-\gamma \phi^{c}(L)
$$

- Abel's Habit Formation Utility (1990 and 1999):

$$
\mu_{m}=\log \delta+[\kappa(\gamma-1)-\gamma] \mu_{c} \text { and } \phi^{m}(L)=-\gamma \phi^{c}(L)+\kappa(\gamma-1) \phi^{c}(L) L
$$

- Epstein and Zin Recursive Utility (1989 and 1991):

Lemma 1: Using log-linear approximation on the budget equation, the log stochastic discount factor under the Epstein and Zin $(1989,1991)$ recursive utility can be approximated as:

$$
m_{t+1}=\mu_{m}+\phi^{m}(L) w_{t+1} .
$$

If the elasticity of intertemporal substitution $\psi=1$, the approximation is exact as shown in Hansen, Heaton and Li (2005) and

$$
m_{t+1, t}=\log \delta-\phi^{c}(L) w_{t+1}-\mu_{c}+(1-\gamma) \phi^{c}(\delta) w_{t+1}-\frac{(1-\gamma)^{2} \phi^{c}(\delta) \cdot \phi^{c}(\delta)}{2},
$$

where $(\cdot)$ represents inner product. This means:

$$
\mu_{m}=\log \delta-\mu_{c}-\frac{(1-\gamma)^{2} \phi^{c}(\delta) \cdot \phi^{c}(\delta)}{2} \text { and } \phi^{m}(L)=-\phi^{c}(L)+(1-\gamma) \phi^{c}(\delta) .
$$

Proof: See Appendix 1.

Elements in $w_{t+1}$ are variables that determine the contemporaneous innovation in consumption growth since $\Delta c_{t+1}-E_{t}\left[\Delta c_{t+1}\right]=\phi^{c}(0) w_{t+1}$. In a consumption-based asset pricing framework, they are likely to be priced. This is reflected in the fact that the SDF is driven by the same variables as in $w_{t+1}$. Therefore, these variables can also be considered as the factors in a factor pricing framework and the factor prices are $\phi^{m}(0) .{ }^{10}$ Appendix 2 provides a detailed discussion.

\section{Cash flow structure of an asset}

Let $S_{t}^{i}$ denote the share of asset $i$ 's cash flow relative to aggregate consumption at time $t$, or:

$$
S_{t}^{i}=\frac{D_{t}^{i}}{C_{t}}
$$

\footnotetext{
${ }^{10}$ See Campbell (1993) for a similar discussion.
} 
Take the log to get:

$$
d_{t}^{i}=s_{t}^{i}+c_{t}
$$

Assumption 3: Log cash flow share follows an AR(1) process:

$$
\begin{aligned}
s_{t+1}^{i} & =(1-\phi) \bar{s}^{i}+\phi s_{t}^{i}+\lambda^{i}\left\{\Delta c_{t+1}-E_{t}\left[\Delta c_{t+1}\right]\right\}+\varepsilon_{t+1}^{i} \\
& =(1-\phi) \bar{s}^{i}+\phi s_{t}^{i}+\lambda^{i} \phi^{c}(0) w_{t+1}+\varepsilon_{t+1}^{i},
\end{aligned}
$$

where $\varepsilon$ is independent of $w$ and $t$.

Cash flow and consumption are cointegrated with the cointegration vector $[1,-1]$. In addition, the cash flow share is stationary and mean-reverting as captured by an AR(1) process. Such specification ensures a stationary steady state where no single asset dominates. ${ }^{11} \lambda^{i}$ is clearly a measure of cash flow covariance. For an asset with larger $\lambda$, its cash flow varies more with the aggregate consumption innovation, resulting in more cash flow covariance. Defining $z_{t}^{i}=\bar{s}^{i}-s_{t}^{i}$ similar to Santos and Veronesi (2004), $z_{t}^{i}$ is a cash flow "duration" measure. An asset with a positive $z_{t}^{i}$ reaches its long-run cash flow share from below. In other words, it pays out more (as a share of aggregate consumption) in the future. $z_{t}^{i}$ is purely cash-flow based, which is different from the usual fix-income definition of duration risk. The latter is price-based, meaning that it measures the change in price as a result of change in discount rate. However, the two duration measures are related as they both capture the temporal pattern of cash flows. In fact, Appendix 3 and Figure 1 show numerically that $z_{t}^{i}$ is monotonically related to the Macaulay duration in the fixed-income literature in an economy similar to that in Bansal and Yaron (2004). The mean reverting speed $\phi$ is also indirectly related to cash flow duration. Menzly, Santos and Veronesi (2004) allows $\phi$ to be asset specific in a similar set-up. Theoretically, my model can incorporate this feature by simply attaching an $i$ superscript to $\phi$ without affecting later results. However, I assume $\phi$ constant across firms for three reasons. First, the empirical estimates of $\phi$ do not vary significantly for most of the 20 industrial portfolios in Menzly, Santos and Veronesi (2004). Second, cross-sectional variation in $\phi$, as opposed to $\lambda$ and $z$, contribute less to cross-sectional variation in expected excess returns, as shown by the calibration and simulation result in Appendix 3. Finally, the assumption of a constant $\phi$ makes the model parsimonious and easily identifiable empirically. $\phi$ will not be accurately estimated empirically given the short sampling period and the need to re-form portfolios every year. Similar assumptions are also made in Dechow, Sloan and Soliman

\footnotetext{
${ }^{11}$ I do not assume that $S_{t}^{i}$ sum up to one across all stocks. In a similar manner to Menzly, Santos and Veronesi (2004), I assume instead that the sum of $S_{t}^{i}$ is strictly smaller than 1 . The difference from 1 accounts for incomes from other sources, for example, labor income.
} 
(2004) and Vuolteenaho (2002b), among others.

Using $z_{t}^{i}$, I can rewrite change in cash flow share in (2) as:

$$
\begin{aligned}
\Delta s_{t+1}^{i} & =(1-\phi) z_{t}^{i}+\lambda^{i} \phi^{c}(0) w_{t+1}+\varepsilon_{t+1}^{i} \\
z_{t+1}^{i} & =\phi z_{t}^{i}-\lambda^{i} \phi^{c}(0) w_{t+1}-\varepsilon_{t+1}^{i} .
\end{aligned}
$$

The cash flow specification is parsimonious in the sense that the two cash flow risks of interest are each captured by one parameter of the model. The specification can be generalized, for instance, to incorporate the cointegration model of Bansal, Dittmar and Lundblad (2002) and Hansen, Heaton and Li (2004). Appendix 2 discusses a very general cash flow structure and derives an approximate analytical expression of risk premium by loglinearizing the stock return. This approach is problematic, nevertheless, because it cannot isolate the impact of cash flow duration. For these reasons, I focus on the simple specification for both analytical tractability and easy economic interpretation. This also serves as a starting point for future extensions that incorporate more realistic cash flow dynamics.

\section{Two-factor Cash Flow Model}

In this section, I derive the exact expression for expected excess stock return under assumption 1 to 3 and use it to motivate the two-factor cash-flow model.

Similar to the continuous-time solution in Brennan, Wang and Xia (2004) and Brennan and Xia (2003) and the discrete-time solution in Lettau and Wachter (2004), I examine the individual cash flow of a stock. Just like a bond, a stock can be considered as a portfolio of claims to future cash flow payments. As mentioned earlier, these cash flow claims are also known as equity strips. Denote $P_{n, t}^{i}$ as the time $t$ price of an equity strip that pays a cash flow $D_{t+n}^{i}$ at time $t+n$. I first compute the price and one-period expected (excess) return for each equity strip. The expected (excess) return of the stock, then, is just the value-weighted average of expected (excess) returns of all equity strips. The results are summarized in the following proposition:

Proposition 1: Under Assumption 1-3, the price-to-cash-flow ratio of equity strip is:

$$
\frac{P_{n, t}^{i}}{D_{t}^{i}}=\exp \left[A^{i}(n)+B(n) z_{t}^{i}+C^{n}(L) w_{t}\right]
$$

where 


$$
B(n)=1-\phi^{n}
$$

and $A^{i}(n)$ and $C^{n}(L)$ are defined in the Appendix 1. The log expected excess return for each equity strip is:

$$
\begin{aligned}
\log E_{t}\left[R_{n, t+1}^{i} / R f_{t}\right] & =R P_{1}^{i}(n)+R P_{2}(n) \\
R P_{1}^{i}(n) & =-\left(1+\phi^{n-1} \lambda^{i}\right) \phi^{c}(0) \cdot \phi^{m}(0) \\
R P_{2}(n) & =-C^{n-1}(0) \cdot \phi^{m}(0)
\end{aligned}
$$

Proof: See Appendix 1.

The risk premium of each equity strip consists of two components. The first component $R P_{1}^{i}(n)$ comes from the contemporaneous covariance between cash flow growth and the SDF. It depends on $\lambda^{i}$ and varies across stocks. Intuitively, the equity strip with higher cash flow covariance, as measured by $\lambda^{i}$, has higher $R P_{1}^{i}(n)$. In addition, $R P_{1}^{i}(n)$ decreases with $n$. For an equity strip with infinite maturity $(n=\infty), R P_{1}^{i}=\phi^{c}(0) \cdot \phi^{m}(0)$ as though the cash flow share has no contemporaneous covariance with consumption growth. This is due to the mean-reversion in cash flow share, so the impact of cash flow covariance diminishes with maturity. As a result, for $\lambda^{i}>0$, $R P_{1}^{i}(n)$ decreases in $n$; for $\lambda^{i}<0, R P_{1}^{i}(n)$ increases in $n$. Therefore the relationship between $R P_{1}^{i}(n)$ and $n$ depends on the cash flow covariance $\lambda^{i}$, consistent with the model in Brennan and Xia (2003). In contrast, the risk premium of the equity strip is always decreases in its maturity in the model of Lettau and Wachter (2004) as they do not allow the cash flow covariance to vary across stocks.

The second component $R P_{2}(n)$ comes from the predictability of consumption growth. If a variable is capable of forecasting aggregate consumption and investors care about long run risk (ex. if they have Epstein and Zin type of preference with elasticity of intertemporal substitution $\psi>1$ ), then that variable's innovation will be correlated with the SDF and therefore priced. It is also important to note that $R P_{2}(n)$ is constant across stocks, partly accounting for the reduced role of expected consumption growth in explaining cross-sectional variation in expected stock returns.

\section{A. Cash flow to price ratio}

Stocks with higher fundamental value (measured by earnings, dividends or book value) to price ratios have higher expected returns than those with lower fundamental value to price ratios. ${ }^{12}$ The

\footnotetext{
${ }^{12}$ See Lakonishok, Shleifer and Vishny (1994) and Lettau and Wachter (2004) for example.
} 
difference is usually called the value spread.

Historically, cash flow to price ratio is considered related to cash flow duration. This reasoning can be easily illustrated in the context of Gordon Growth Model:

$$
P_{t}^{i}=\frac{D_{t+1}^{i}}{r-g_{t}^{i}}
$$

where $g_{t}^{i}$ is the expected dividend growth rate at time $t$ and $r$ is a constant discount rate. Compute the fix-income definition of modified duration $\left(M D_{t}^{i}\right)$ :

$$
M D_{t}^{i}=-\frac{\partial P_{t}^{i} / P_{t}^{i}}{\partial r}=\frac{1}{D_{t+1}^{i} / P_{t}^{i}}
$$

Therefore, the cash flow to price ratio is inversely related to modified duration in this simple constant discount rate model. ${ }^{13}$ Since the concept of modified duration is price-based, it reflects all dimensions of cash flow risks, including both cash flow covariance and duration.

Consider the cash flow to price ratio in my simple cash flow model:

$$
\frac{D_{t}^{i}}{P_{t}^{i}}=\frac{1}{\sum_{n=1}^{\infty} \exp \left\{A^{i}(n)+B(n) z_{t}^{i}+C^{n}(L) w_{t}\right\}} .
$$

Since $B(n)>0$, the cash flow to price ratio is also decreasing with the cash flow duration measure $z$. Therefore, value stocks are associated with lower duration. The impact of cash flow covariance $\lambda$ is less clear. Nevertheless, for not too large a $\lambda$, the cash flow to price ratio is increasing in $\lambda$. This relationship is confirmed by numerical calibrations in Appendix 3 and Figure 2. To summarize, a stock with high cash flow covariance and low cash flow duration will have a high cash flow to price ratio, and is likely to be classified as a value stock. On the other hand, a stock with low cash flow covariance and high cash flow duration will have a low cash flow to price ratio, and is likely to be classified as a growth stock. The fact that cash flow to price ratio is related to a similar cash flow duration measure is also highlighted in Menzly, Santos and Veronesi (2004).

\section{B. Expected return}

The expected (excess) return of a stock is just the value-weighted average of expected (excess) returns of all equity strips:

\footnotetext{
${ }^{13}$ This relationship has been discussed earlier in Lintner (1975) and Santa-Clara (2004).
} 


$$
\begin{aligned}
E_{t}\left[R_{t+1}^{i} / R f_{t}\right] & =\frac{\sum_{n=1}^{\infty} P_{n, t}^{i} E_{t}\left[R_{n, t+1}^{i} / R f_{t}\right]}{P_{t}^{i}} \\
& =\frac{\sum_{n=1}^{\infty} P_{n, t}^{i} \exp \left[R P_{1}^{i}(n)+R P_{2}(n)\right]}{P_{t}^{i}}
\end{aligned}
$$

The expected excess return can also be decomposed into two parts approximately:

$$
\begin{aligned}
E_{t}\left[R_{t+1}^{i}-R f_{t}\right] & \approx R P_{1, t}^{i}+R P_{2, t}^{i} \\
R P_{1, t}^{i} & =\frac{\sum_{n=1}^{\infty} P_{n, t}^{i} R P_{1}^{i}(n)}{P_{t}^{i}} \\
R P_{2, t}^{i} & =\frac{\sum_{n=1}^{\infty} P_{n, t}^{i} R P_{2}(n)}{P_{t}^{i}}
\end{aligned}
$$

\section{An approximation}

The two-factor cash flow model can be motivated from a quadratic approximation of the true asset pricing model (3):

$$
E_{t}\left[R_{t+1}^{i}-R f_{t}\right] \approx \gamma_{0}+\gamma_{1} \lambda^{i}+\gamma_{2}\left(z_{t}^{i} \lambda^{i}\right)+\gamma_{3} z_{t}^{i}+\gamma_{4}\left(\lambda^{i}\right)^{2}+\gamma_{5}\left(z_{t}^{i}\right)^{2} .
$$

(4) can be seen as a Taylor approximation of (3). For not too big $\lambda^{i}$ and $z_{t}^{i}$, and small last terms, we have:

$$
E_{t}\left[R_{t+1}^{i}-R f_{t}\right] \approx \gamma_{0}+\gamma_{1} \lambda^{i}+\gamma_{2}\left(z_{t}^{i} \lambda^{i}\right)+\gamma_{3} z_{t}^{i}
$$

The second term $\gamma_{1} \lambda^{i}$ and the third term $\gamma_{2}\left(z_{t}^{i} \lambda^{i}\right)$ come mainly from $R P_{1, t}^{i}$. We would expect $\gamma_{1}$ to be positive since, intuitively, more cash flow covariance should lead to higher expected risk. We also expect $\gamma_{2}$ to be negative, reasoning as follows: when $\lambda^{i}>0, R P_{1}^{i}(n)$ decreases in $n$; a stock with higher duration $z_{t}^{i}$ puts more weights on equity strips with longer maturities. As a result, the weighted-average $R P_{1, t}^{i}$ is lower since longer maturities equity strips have lower expected returns. The reverse logic holds for $\lambda^{i}<0$. Finally, the third term $\gamma_{3} z_{t}^{i}$ comes mainly from $R P_{2, t}^{i}$. For the same reason as above, if $R P_{2}(n)$ increases (decreases) with $n$, then higher $z_{t}^{i}$ leads to higher 
(lower) $R P_{2, t}^{i}$, resulting in a positive (negative) $\gamma_{3}$. However, if $R P_{2}(n)$ does not vary significantly with $n$, then $R P_{2, t}^{i}$ will not change with $z_{t}^{i}, \gamma_{3}$ will be close to zero, and the two-factor cash flow model of (1) will be a good approximation. This last assumption depends on, among other things, preference parameters, aggregate consumption dynamics and cross-sectional variation in cash flow covariance and duration. The approximation of the true asset pricing model (3) using a two factor cash flow model (1) is illustrated graphically in Figure 3.

Appendix 3 works out the cross-sectional implication of the mean-reverting cash flow share in Bansal and Yaron's (2004, BY thereafter) economy, in which: (1) consumption growth contains a small long-run predictable component; (2) there is time-varying economic uncertainty; (3) investors have Epstein and Zin's utility and care about long run risks. A numerical calibration exercise is conducted. It shows that (a) time-varying expected consumption growth and (b) time-varying volatility make relatively small contributions to cross-sectional variation in expected returns. Thus, the two-factor cash flow model still does a good job in the cross-section. This Appendix also serves as a self-contained worked out example of the model intuition. More interestingly, I want to know whether the two-factor cash flow model is a reasonable description of the cross-sectional relationship between cash flow characteristics and the expected risk premium in the data. This will be the targeted focus of the next section.

\section{Empirical Analysis}

This section tests empirically the relationship between cash flow risk and expected (excess) return. I focus on the linear approximation of the true model (3):

$$
E_{t}\left[R_{t+1}^{i}-R f_{t}\right]=\gamma_{0}+\gamma_{1} \lambda^{i}+\gamma_{2}\left(z_{t}^{i} \lambda^{i}\right)
$$

Taking the unconditional expectation, we have:

$$
E\left[R_{t+1}^{i}-R f_{t}\right]=\gamma_{0}+\gamma_{1} \lambda^{i}+\gamma_{2} E\left[z_{t}^{i}\right] \lambda^{i} .
$$

The cash flow duration $E\left[z_{t}^{i}\right]$ and cash flow covariance $\lambda^{i}$ are estimated at the portfolio level. ${ }^{14}$

The empirical procedure in this paper is similar to that used in Cohen, Polk and Vuolteenaho (2003b). It differs from previous studies of cash flow consumption risk in two important ways. ${ }^{15}$ First, those studies estimate cash flow of a portfolio while rebalancing the portfolio over time,

\footnotetext{
${ }^{14} E\left[z_{t}^{i}\right]$ in this section denotes expected portfolio cash flow duration at formation (the composition of the portfolio $i$ changes across $t$ ). It does NOT denote the unconditioanl expectation of cash flow duration for a fixed portfolio, which is always zero given the $A R(1)$ assumption on the cash flow share.

${ }^{15}$ See Bansal, Dittmar and Lundblad (2002), Hansen, Heaton and Li (2004), Menzly, Santos and Veronesi (2004) and Santos and Veronesi (2004)
} 
introducing two problems: (1) portfolio cash flow will depend on the stock prices at the time of rebalancing, which are subject to mispricing risk, and (2) if the composition of a portfolio continues changing, it becomes impossible to estimate its cash flow duration from the resulting cash flow. ${ }^{16}$ To avoid these two problems, whenever a portfolio is formed, I will hold its composition constant and trace out its cash flow over time. Second, those studies measure cash flow using dividend (including share repurchase) data. At a short horizon, dividend is particularly problematic. There are firms expected to pay no dividend for a long time into the future and most firms tend to keep a stable dividend payout policy in the near future. ${ }^{17}$ Taking these into consideration, I use instead the theoretically equivalent, but empirically better behaved, earnings data to estimate cash flow characteristics.

\section{A. Identification of cash flow duration and covariance}

Since I form and hold portfolios on a yearly basis, the cash flow data has three dimensions: the number of portfolios in a cross-section times the number of years I follow the portfolios times the number of years in the sampling period. Let $s^{i}(t, n)$ denote the cash flow share at $n$th year after portfolio formation for portfolio $i$ formed in year $t$. Then according to the cash flow specification of $(2)$,

$$
\begin{aligned}
\Delta s^{i}(t, n+1) & =(1-\phi) z^{i}(t, n)+\lambda^{i} \phi^{c}(0) w_{t+n+1}+\varepsilon_{t+n+1}^{i}, \\
z^{i}(t, n+1) & =\phi z^{i}(t, n)-\lambda^{i} \phi^{c}(0) w_{t+n+1}-\varepsilon_{t+n+1}^{i}, \\
E\left[z_{t}^{i}\right] & =E\left[z^{i}(t, 0)\right] .
\end{aligned}
$$

\section{A.1. Moving from cash flow to earning}

Clean-surplus identity implies:

$$
B_{t+1} \equiv B_{t}+X_{t+1}-D_{t+1}
$$

\footnotetext{
${ }^{16}$ To see this, consider an extreme case: if, every year, a portfolio is rebalanced to include firms expected to pay out nothing in the coming year (for example, current growth firms), then the resulting cash flow from this portfolio will be uniformly zero throughout. There will be no way to estimate the duration risk of the portfolio at formation (although we expect growth firms have high cash flow durations).

${ }^{17}$ There are several reasons why dividend may be "sticky," explained in Chapter 14 of Damodaran's (2003) "Investment Valuation".
} 
where $B, X$ and $D$ denote book value of equity, earning and cash flow, respectively. ${ }^{18}$ Therefore, log accounting return can be written as:

$$
e_{t+1}=\log \left(\frac{B_{t+1}+D_{t+1}}{B_{t}}\right)=\log \left(1+\frac{X_{t+1}}{B_{t}}\right)=\log \left(1+R O E_{t+1}\right) .
$$

Denoting the log cash-flow-to-book-equity ratio, $\gamma_{t}=d_{t}-b_{t}$, we have:

$$
e_{t+1}=\log \left(\exp \left(-\gamma_{t+1}\right)+1\right)+\Delta d_{t+1}+\gamma_{t} \text {. }
$$

Consider a log-linear approximation first proposed by Vuolteenaho (1999):

$$
e_{t+1} \approx \kappa-\rho \gamma_{t+1}+\Delta d_{t+1}+\gamma_{t}
$$

$\rho$ typically takes a value around 0.95 and the constant $\kappa$ is related to $\rho$ by: ${ }^{19}$

$$
\kappa=-(1-\rho) \log (1-\rho)-\rho \log (\rho) .
$$

Empirically, I choose $\rho=0.95$. As a result, $\kappa=0.1985$.

Rearrange (7) to get:

$$
\Delta d_{t+1}=e_{t+1}-\kappa+\rho \gamma_{t+1}-\gamma_{t}
$$

Compute the following expression:

$$
\begin{aligned}
& \sum_{n=0}^{\infty} \rho^{n} \Delta d(t, n+1) \\
= & \sum_{n=0}^{\infty} \rho^{n} e(t, n+1)-\frac{\kappa}{1-\rho}-\gamma_{t},
\end{aligned}
$$

where I assume:

$$
\lim _{n \longrightarrow \infty} \rho^{n} \gamma_{t+n}=0
$$

(8) essentially states that if we look ahead for an infinite horizon, cash flow and earnings data contain the same information. The limitation in historical data confines us to looking ahead at a finite horizon; therefore, using earnings data may be better for at least two reasons. First, for

\footnotetext{
${ }^{18}$ I drop the subscript $i$ hereafter for simplicity.

${ }^{19}$ In fact, $\rho=\frac{1}{1+\overline{D / B}}$ where $\overline{D / B}$ denotes the average book dividend yield. Therefore, the choice of $\rho=0.95$ corresponds to an average book dividend yield of $5.26 \%$, close to its historical value.
} 
firms that are not expected to pay dividend in the foreseeable future, looking at earnings data is our only feasible choice. Second, return on book equity $(e)$ is empirically more stationary, which gives statistically better-behaved estimates. At annual horizon, earnings data may suffer from management's discretionary choices on the timing of accruals and other types of accounting manipulations as documented in Jones(1991), Teoh, Welch and Wong (1998a and 1998b) and Chan, Chan, Jegadeesh and Lakonishok (2001) among others. However, the impact of such earning management will be significantly reduced if earning is "smoothed" over much longer horizon as implicitly incorporated in (8).

\section{A.2. Cash flow duration}

The LHS of (8) is:

$$
\sum_{n=0}^{\infty} \rho^{n} \Delta d(t, n+1)=\sum_{n=0}^{\infty} \rho^{n} \Delta s(t, n+1)+\sum_{n=0}^{\infty} \rho^{n} \Delta c_{t+n+1} .
$$

Take unconditional expectation at both sides, since:

$$
\begin{aligned}
E\left\{\sum_{n=0}^{\infty} \rho^{n} \Delta s(t, n+1)\right\} & =E\left\{E_{t}\left[\sum_{n=0}^{\infty} \rho^{n} \Delta s(t, n+1)\right]\right\} \\
& =E\left\{E_{t}\left[\sum_{n=0}^{\infty} \rho^{n}(1-\phi) z(t, n)\right]\right\} \\
& =\frac{1-\phi}{1-\rho \phi} E\left[z_{t}\right]
\end{aligned}
$$

and

$$
E\left\{\sum_{n=0}^{\infty} \rho^{n} \Delta c_{t+n+1}\right\}=\frac{\mu_{c}}{1-\rho}
$$

then cash flow duration can be identified up to a scaling factor:

$$
\text { Dur }=E\left[\Sigma_{t}^{e}-\frac{\kappa+\mu_{c}}{1-\rho}-\gamma_{t}\right] \propto E\left[z_{t}\right]
$$

where

$$
\Sigma_{t}^{e}=\sum_{n=0}^{\infty} \rho^{n} e(t, n+1)
$$


The term $E\left[\Sigma_{t}^{e}\right]$ measures the discounted sum of all future accounting returns. The relation in (9) is very intuitive: higher duration means higher cash flow growth in the near future. This is either because future earnings (as measured by $E\left[\Sigma_{t}^{e}\right]$ ) are high which finances higher future cash flow payout, or because the current cash flow (as measured by $E\left[\gamma_{t}\right]$ ) is low, providing a low base for higher future growth.

Empirically, I estimate the $\mu_{c}$ and $E\left[\gamma_{t}\right]$ by time-series averages of log consumption growth and log portfolio cash-flow-to-book-equity ratio at portfolio formation, respectively. To estimate the term $E\left[\Sigma_{t}^{e}\right]$, I first break it into two parts: a finite summation term and the terminal value term:

$$
E\left[\Sigma_{t}^{e}\right]=E\left\{\sum_{n=0}^{N-1} \rho^{n} e(t, n+1)+\sum_{n=N}^{\infty} \rho^{n} E_{t}[e(t, n+1)]\right\} .
$$

If for each fixed $t,\{e(t, n), n=1, \ldots, \infty\}$ is a stationary mean reverting process with mean $\bar{e}_{t}$, then for large value of $N$,

$$
E_{t}[e(t, N+1)] \approx \bar{e}_{t}
$$

and

$$
\sum_{n=N}^{\infty} \rho^{n} E_{t}[e(t, n+1)] \approx \frac{\rho^{N}}{1-\rho} \bar{e}_{t} .
$$

$\bar{e}_{t}$ in turn can be estimated by time-series average of $\{e(t, n), n=1, \ldots, N\}$. The procedure is conservative: for a portfolio whose cash flow share takes longer time to reach its steady state, this procedure will bias the duration estimate towards zero. .

\section{A.3. Cash flow covariance}

To estimate the cash flow covariance $\lambda^{i}$, consider:

$$
\operatorname{cov}\left(\sum_{n=0}^{\infty} \rho^{n} \Delta s(t, n+1), \sum_{n=0}^{\infty} \rho^{n} \phi^{c}(0) w_{t+n+1}\right)=\operatorname{cov}\left(\sum_{n=0}^{\infty} \rho^{n}\left[e(t, n+1)-\Delta c_{t+n+1}\right], \sum_{n=0}^{\infty} \rho^{n} \phi^{c}(0) w_{t+n+1}\right) .
$$

In my model specification, the LHS is:

$$
\frac{1}{(1-\phi \rho)(1+\rho)} \lambda^{i} \phi^{c}(0) \cdot \phi^{c}(0)
$$


Therefore, $\lambda^{i}$ can be identified by regressing $\sum_{n=0}^{\infty} \rho^{n}\left[e(t, n+1)-\Delta c_{t+n+1}\right]$ on $\sum_{n=0}^{\infty} \rho^{n} \phi^{c}(0) w_{t+n+1}$. I denote the regression coefficient Cov, which measures $\lambda^{i}$ up to a scaling factor. Empirically, I replace the infinite summation by a finite summation. This summation also acts as a "smoothing" mechanism, which alleviates possible measurement errors due to earning management and seasonal adjustment in consumption data. Following Bansal and Yaron (2002), I assume $\Delta c_{t+1}$ follows an $\operatorname{ARMA}(1,1)$ process and the residual terms will be the estimates of $\left\{\phi^{c}(0) w_{t}\right\} .{ }^{20}$

\section{B. Data construction}

Quarterly log aggregate consumption $(c)$ data are used. ${ }^{21}$ I measure $\Delta c_{t}$ annually (fourth quarter to fourth quarter) to match the cash flow data series. In addition, since investors are more likely to make consumption and investment decisions together during the fourth quarter, fourth quarter to fourth quarter consumption growth better explains cross-sectional stock returns, as shown in Jagannathan and Wang (2005).

Data used for cash flow estimation comes from the intersection of CRSP and COMPUSTAT. Every June starting from 1964, I group all stocks issued by industrial firms ${ }^{22}$ in NYSE, AMEX and NASDAQ into 10 size-sorted portfolios and 10 book-to-market-sorted portfolios. I follow FamaFrench's procedure wherever possible. Book equity is defined as stockholders's equity plus deferred tax and investment tax credit (COMPUSTAT data item 35) minus the book value of preferred stocks. Depending on availability, I use data item 216, book value of common equity (data item 60) plus book value of preferred stock, or book value of assets (data item 6) minus total liabilities (data item 181), in that order, for stockholders's equity. I use redemption (data item 56), liquidation (data item 10), or par value (data item 130) (in that order) for book value of preferred stock. The book-to-market ratio in June of year $t$ is book equity for the fiscal year ending in calendar year $t-1$, divided by market equity at the end of Dec of year $t-1$. Size is defined as market equity at the end of June of year $t$. To avoid potential data error and extreme outliers, I exclude stocks whose book-to-market ratios exceed the 99 percentile or fall below the 1 percentile. In addition, I exclude stocks whose book-to-market ratios are negative. I record the first year annual returns of the portfolios after their formations. Following Shumway (1997), I assign a return of -0.3 to firm delisted for performance related reasons. ${ }^{23}$ Details on these computations and the merger of

\footnotetext{
${ }^{20}$ I have considered other parameteric specifications of $\Delta c_{t+1}$, including the $\mathrm{AR}(1)$, as in Prescott and Mehra (1985) and the VAR specification, as in Lettau and Ludvigson (2001). These estimates of covariance risk are very similar.

${ }^{21}$ I thank Sydney Ludvigson for making this data available at http://www.econ.nyu.edu/user/ludvigsons/. The data are available from 1951Q2 to 2005Q1. Detailed information on the data construction can be found in the Appendix of Lettau and Ludvigson (2001).

${ }^{22}$ I exclude financial firms (SICCD in [6000, 6999]) and utilities companies (SICCD in [4900, 4999]).

${ }^{23}$ Delisting code is 500 or in $[520,584]$.
} 
CRSP and COMPUSTAT data can be found in Da, Gao and Wang (2004). Description of the data are contained in Table 2. The sampling period is from 1964 to 2002.

Each year $t$, after I form the 20 portfolios, I hold them for 12 years as illustrated in Figure 4. All accounting cash flow data are converted to real term using the PCE deflator. I record the return on equity $(R O E)$ of each portfolio from year $t+1$ to year $t+12$. Following Vuolteenaho (2002), I define $R O E_{t}$ as aggregate portfolio earnings measured according to the U.S. Generally Accepted Accounting Principles (GAAP) (COMPUSTAT data item 172) at year $t$ divided by aggregate portfolio book equity at year $t-1$. For firms that disappear due to delisting, merger or acquisition, I assume we invest the proceeds from such activities in the original portfolios where the disappeared firms belong. In this way, the portfolio $R O E$ number will not be altered. ${ }^{24}$ At the portfolio level, the $R O E$ number is well above -1 , so I can safely compute $e=\log (1+R O E)$ without risking the number in the bracket to be negative or too close to 0. Finally, I also compute the portfolio cash-flow-to-book-equity ratio at portfolio formation, which will be used later in computing cash flow duration. This ratio is defined as aggregate portfolio common dividend plus common share repurchase at the portfolio formation year divided by aggregate portfolio book equity also at the portfolio formation year. Common dividend is measured using COMPUSTAT data item 21. Following Grullon and Michaely (2002), common share repurchase is defined as expenditure on the purchase of common and preferred stocks (data item 115) minus any reduction in the book value of preferred stock.

I directly test the stationarity of the log cash flow share using the Augmented Dickey - Fuller test with a constant and a lag of one. The log cash flow share in year $t$ is computed as the log of the ratio between the portfolio cash flow (sum of common dividend and common share repurchase) and aggregate consumption during year $t$. The sampling period is again from 1964 to 2002, so I have a time series of 38 cash flow shares for each of the 20 portfolios. The alternative hypothesis on the existence of a unit root is rejected for most of the 20 portfolios (17 out of 20) as in Table 2. In addition, I also test the $\mathrm{AR}(1)$ assumption on the log cash flow share by examining whether the $\mathrm{AR}(1)$ residuals are white noises. This is in turn done using the Ljung-Box $\mathrm{Q}$ test. The p-values associated with the tests are higher than 0.1 for almost all the portfolios (19 out of 20), which means the AR(1) assumption cannot not be rejected. In conclusion, the AR(1) assumption imposed on the log cash flow share seems to be reasonable at least at the portfolio level.

\footnotetext{
${ }^{24}$ The disappearing firms account for a relatively small portion of these portfolios. I define an exit ratio for each portfolio and each year as the total market value (at begining of the year) of firms that exit the portfolio during the year divided by the total portfolio market value (at begining of the year). The average exit ratio is only $2.2 \%$ across the 20 portfolios for the first 10 years after portfolio formation. The exit ratio is the largest for the smallest size portfolio, which is $4.4 \%$.
} 


\section{Cash flow characteristics and the cross-sectional regression results}

Table 3 breaks down the cash flow duration as measured by (9) for the 20 portfolios. I choose $N=5$ when estimating the term $E\left[\Sigma_{t}^{e}\right]$. Due to 5 year holding period of a portfolio, the sampling period is reduced from 1964-2002 to $1964-1997 .{ }^{25}$ The average consumption growth in this period is about $2 \%$, so the term $\left(\kappa+\mu_{c}\right) /(1-\rho)$ is equal to 4.43 . The t-values are computed using GMM standard errors which account for both cross-sectional and time-series error correlations using the Newey-West formula of 5 leads and lags. I report the differences in the cash flow duration estimates between extreme portfolios in the last two columns.

Panel A contains duration estimates for 10 book-to-market-sorted portfolios. The cash flow duration measure Dur decreases monotonically in book-to-market ratio. As expected, growth stocks have higher cash flow durations than value stocks. The difference in Dur between two extreme portfolios is 1.36 and highly significant. The high duration of growth stock is largely driven by higher earnings in the future. Both $E\left[\Sigma_{t}^{e}\right]$ and $E\left[\gamma_{t}\right]$ decrease in book-to-market ratio, which means growth stocks have, on average, both higher future earnings and higher current accounting payout ratios. ${ }^{26}$ Since $E\left[\Sigma_{t}^{e}\right]$ decreases faster than $E\left[\gamma_{t}\right]$ as we move from growth stock to value stock, the impact of higher future earnings dominates, resulting in higher cash flow durations for growth stocks.

Panel B contains duration estimates for 10 size-sorted portfolios. In general, small stocks have lower cash flow durations than big stocks. This is because most of the traded small stocks are "distressed" stocks and their cash flows, if any, are expected to decrease in the future. Both $E\left[\Sigma_{t}^{e}\right]$ and $E\left[\gamma_{t}\right]$ increase in size, but $E\left[\Sigma_{t}^{e}\right]$ increases more. Evidently, the impact of future earnings again dominates. Lastly, the difference in Dur between two extreme size-sorted portfolios is calculated to be 0.87 (in absolute term). Sorting on size, then, induces a smaller spread in cash flow durations than sorting on book-to-market-ratio. A bias may partly contribute to this pattern, as I sort stocks according to book-to-market ratios. ${ }^{27}$ If we underestimate the book equity value for a stock, we tend to sort that stock to growth portfolios as a result. This error in measurement will also increase $E\left[\Sigma_{t}^{e}\right]$, resulting in an increase in the duration measure. Even if this bias is accounted for the pattern will not likely change because the difference in duration measures between extreme growth and value stocks is so significant (with a robust t-value above 6).

Table 4 contains the cash flow covariance as measured by (10) for the 20 portfolios. I replace the infinite sum in (10) by a finite sum up to $N$, presenting estimates for $N=5,7,10$ and 12 . Due

\footnotetext{
${ }^{25}$ For this reason, I do not choose a very large $N$.

${ }^{26}$ One would expect growth stocks to pay out less to finance future growth. This is indeed true as in Panel A of Table 2 when the payout is measured by cash-flow-to-price ratio. However, growth stocks have much smaller book values (the average book-to-market ratio for growth stocks is only 0.155), resulting in large accounting payout ratios.

${ }^{27}$ This is also pointed out in Cohen, Polk and Vuolteenaho (2003b).
} 
to the need to hold portfolios $N$ years ahead, the sampling period associated with each $N$ spans from 1964 to 2002 - $N$. The estimates of Cov are obtained using overlapping OLS regressions. As with Dur, I compute robust t-values for Cov using GMM standard errors which account for both cross-sectional and time-series error correlations with Newey-West formula of $N$ leads and lags. As predicted, value (small) stocks have higher cash flow covariance measures than growth (large) stocks in general for all $N$. A large $N$ makes the estimate closer to its theoretical counterpart. On the other hand, a large $N$ accumulates measurement errors in cash flow data and also reduces the sample size, both of which makes the estimates empirically less accurate. If we look at the t-values associated with the spread in covariance risks between two extreme portfolios across $N$, they first increase and then drop. Since this spread is most significant at a horizon of $N=7$, I choose the cash flow covariance estimates associated with $N=7$ for the cross-sectional analysis.

I test the expected excess return relationship (6) in a cross-section. Empirically, I estimate:

$$
E\left[R_{t+1}^{i}-R f_{t}\right]=\gamma_{0}+\gamma_{1} \operatorname{Cov}+\gamma_{2} \operatorname{Cov} \times \text { Dur } .
$$

The next period earning surprise is empirically correlated with the next period return innovation, and since I estimated Dur using forward-looking earning data, such correlation may bias a time-series predictive regression such as:

$$
R_{t+1}^{i}-R f_{t}=\gamma_{0}+\gamma_{1} \lambda^{i}+\gamma_{2}\left(z_{t}^{i} \lambda^{i}\right)+\varepsilon_{t+1}^{i} .
$$

Nevertheless, the correlation should not affect an unconditional cross-sectional regression such as (1), since both Dur and $E\left[R_{t+1}^{i}-R f_{t}\right]$ are unconditional expectation and estimated using time-series average. Earning surprise will be averaged out across time and will not introduce any bias as the number of years approaches infinity. Empirically, the unconditional expectation is computed by averaging about 35 observations, therefore some bias may still remain. If so, one would expect expected excess return to be positively correlated with duration. But this is not the case in the data: high book-to-market and small stocks with low Dur measures have higher excess returns. Therefore, forward looking bias, if it exists, should work against the two-factor cash flow model. To further demonstrate that forward-looking bias does not significantly impact the estimates, I break the sampling period into two halves and use the first half to estimate Dur and Cov. The two estimates are used, in turn, to explain the cross-sectional variations in expected excess returns in the second half. The results hardly differ from the full sample results, but the statistical power of the test is much lower. For this reason, I will only report the results estimated using the full sample. Finally, in the next subsection, I also estimate an "ex-ante" measure of cash flow duration - $\widehat{D u r}$ using only currently observable instrument variables. When I replace Dur with $\widehat{D u r}$ in the cross-sectional regression, the results again hardly change. 
The estimates of $\gamma_{0}, \gamma_{1}$ and $\gamma_{3}$ are obtained using OLS regressions, whereas the associated robust t-values are computed using GMM standard errors. I stack moment conditions in both the time-series and cross-sectional regressions in a one-stage GMM system, similar to those discussed in Cochrane (2001)and Bansal, Dittmar and Lundblad (2002). The moment conditions are chosen such that the resulting GMM system produces point estimates identical to those in an OLS regression. The covariance matrix of the moment conditions are computed using Newey-West formula of 7 leads and lags. The resulting robust t-values account for errors both cross-sectionally and in time-series. In particular, they adjust for estimation errors in both Cov and Dur in the time-series regression. The details of this procedure for the two-factor cash flow model are worked out in Appendix A4.1. For comparative purposes, I also run the more commonly used Fama-MacBeth regressions and report the associated t-values. ${ }^{28}$

I estimate three alternative return-based models as benchmarks. They are: (1) the standard CAPM:

$$
E\left[R_{t+1}^{i}-R f_{t}\right]=\gamma_{0}+\gamma_{1} \beta_{M K T}
$$

(2) the standard Consumption-based CAPM estimated using returns:

$$
E\left[R_{t+1}^{i}-R f_{t}\right]=\gamma_{0}+\gamma_{1} \beta_{\Delta c}
$$

and (3) the Fama-French three factor model: ${ }^{29}$

$$
E\left[R_{t+1}^{i}-R f_{t}\right]=\gamma_{0}+\gamma_{1} \beta_{M K T}+\gamma_{2} \beta_{S M B}+\gamma_{3} \beta_{H M L} .
$$

The cross-sectional regression results are presented in Table 5. The cash flow covariance measure alone explains $64 \%$ of the cross-sectional variations in expected excess returns. After adding in a second factor, Cov $\times$ Dur, which contains cash flow duration, Cov remains significant. However, the second factor is also significant which means that cash flow duration still has additional explanatory power. The R-square from the addition of this factor increases to $82 \%$. The incremental R-square of adding the second factor is $18 \%$, close to the level predicted by the numerical simulation in Appendix A3.3. Finally, the coefficient on the second factor Cov $\times$ Dur is negative, consistent with the theoretical prediction and simulation result- that is, cash flow duration increases expected return when cash flow covariance is negative; reduces expected return when cash flow covariance is positive, as demonstrated in Figure 2. The cash flow model also compares favorably against alternative models estimated using return data. The one-factor cash flow model with only cash flow covariance performs slightly better than the standard CCAPM in which con-

\footnotetext{
${ }^{28}$ Fama-MacBeth regression produces point estimates identical to an OLS regression using the mean values.

${ }^{29}$ I thank Ken French for providing data on the three factors.
} 
sumption beta is estimated using returns. The one factor model yields a higher R-square and more significant consumption risk premium. The two-factor cash flow model performs better than the three factor model in terms of a higher R-square and more significant risk premium.

Figure 5 contains a graphic representation of the these results. The cash flow model with only cash flow covariance, which can stand in as a first-order approximation of the true model, does explain a reasonable large portion of the cross-sectional variation in expected excess returns. However, the relationship between realized and fitted expected excess return is still somewhat nonlinear, largely due to the omission of the second order effect. The second order effect is well captured by the second factor Cov $\times$ Dur, an interaction term between cash flow covariance and duration. If we account for this second order term explicitly in a two-factor cash flow model, the relationship between realized and fitted expected excess return becomes linear. The two-factor cash flow model accounting for cash flow duration well explains the expected excess returns of all 20 portfolios including the smallest size portfolio and lowest book-to-market portfolio where all other models slightly falter.

\section{An ex-ante cash flow duration measure}

To further alleviate concerns about the "forward-looking bias" in estimating cash flow duration, I estimate an "ex-ante" measure of cash flow duration - $\widehat{D u r}$ in this subsection. Recall my cash flow duration measure at time $t$ :

$$
\operatorname{Dur}_{t}=\Sigma_{t}^{e}-\frac{\kappa+\mu_{c}}{1-\rho}-\gamma_{t} .
$$

Only the term $\Sigma_{t}^{e}$ involves forward-looking earnings data and is therefore not measurable at $t$; however, we can apply a predictive regression to obtain an "ex-ante" prediction of $\Sigma_{t}^{e}$. Specifically, each year from 1965 to 1999 , I compute $\Sigma_{t}^{e}$ for each of my 20 portfolios and regress $\Sigma_{t}^{e}$ on a set of instruments $X$ in a balanced panel setting:

$$
\overline{\Sigma_{t}^{e}}=\beta \bar{X}+u
$$

Variables with upper bars are cross-sectionally demeaned so there is no constant term in (13). In choosing the variables, I try to avoid variables containing price information since one of the main objective of this paper is to measure risk using only accounting cash flow information. The variables I decide to include in the vector $X$ are: $\log$ current $\operatorname{ROE}\left(e_{t}=\log \left(1+R O E_{t}\right)\right), \log$ current book dividend yield $\left(D I V_{t}=\log \left(1+D_{t} / B_{t}\right)\right)$ and the percentage sales growth from year $t-1$ to year $t\left(S G_{t}=\right.$ Sales $_{t} /$ Sales $\left._{t-1}-1\right)$. Details on the robust standard error calculation can be found in Appendix A4.2. 
Results of the regression are provided in Panel A of Table 6. The three variables are able to explain a large portion of the cross-sectional variation in $\Sigma_{t}^{e}$ with R-square of above 0.8 over the full sample. I also repeat the same panel regression in two subsamples and obtain qualitatively similar results. ${ }^{30}$ The regression coefficients - $\beta$ on all three variables are positive as we would expect. Since $R O E$ is persistent, high current earning is likely to be associated with high earnings in the near future, resulting in a positive coefficient on $e_{t}$. The positive coefficient on $D I V_{t}$ is consistent with the empirical relation in Table 3 and $4: \Sigma_{t}^{e}$ is positively correlated with book dividend yield $\gamma_{t}$, since firms facing more growth opportunities tend to pay less dividends. Finally, the coefficient on $S G_{t}$ is also positive since higher sales growth indicates greater growth potential in the future. The coefficients on $e_{t}$ and $D I V_{t}$ are highly significant while the coefficient on $S G_{t}$ are significant in the later subsample but not in the early subsample.

Once I estimate the regression (13), I can compute the "ex-ante" cash flow duration measure (up to a constant) for each of the 20 portfolios as:

$$
\widehat{D u r}_{t}=\widehat{\beta} X_{t}-\frac{\kappa+\mu_{c}}{1-\rho}-\gamma_{t}
$$

Panel B of Table 6 reports average sample values of $e, D I V, S G$ and the average sample estimates of $\widehat{D u r}$ for each of the 20 portfolios. The growth stock portfolio, with higher $e, D I V$ and $S G$, has higher cash flow duration than the value stock portfolio. The small stock portfolio, with lower $e, D I V$ and $S G$, has lower cash flow duration than the big stock portfolio. If we replace the previous cash flow duration measure Dur with the ex-ante cash flow duration measure $\widehat{D u r}$ in the cross-sectional regression, the results hardly change as in Panel $\mathrm{C}$ of Table 6. This is not surprisingly given the large predictive power of our instrument variables.

\section{E. Additional diagnostic regressions}

The success of the two-factor cash flow model implies that it is the interaction term Cov $\times$ Dur which provides additional explanatory power. In fact, if I include Dur alone as the second factor in the cross-sectional regression, it does not help as seen from Panel A of Table 7. The R-square hardly improves and cash flow duration has an insignificant risk premium.

Intuitively, dividend yield is inversely related to cash flow duration. However, since dividend yield is computed using price, which reflects all type of risks, it may not be a "clean" measure of

\footnotetext{
${ }^{30}$ Finanlly, I also examine the rolling-window estimates of cash flow duration measure. At each year, I re-estimate (13) using data from 1965 through the current year, so the duration measure $\widehat{D u r}_{t}$ is only computed using information available at year $t$. For this calculation, I start my portfolio construction at year 1975 so I have enough data to compute reasonably reliable estimates of $\widehat{D u r}_{t}$ even during early years. Such rolling-window estimation provides similar cash flow duration measures for the 20 portfolios.
} 
cash flow duration. In order to see this, if I were to replace Dur with $D / P$ - the dividend yield where $D$ includes both common dividend payout and common share repurchase - the dividend yield does not provide additional explanatory power as shown in Panel B of Table 7. The second factor $\operatorname{Cov} \times D / P$ is insignificant and the adjusted R-square of the two-factor model is almost identical to that of the one factor model.

As a model misspecification check, I include portfolio characteristics as additional variables in the cross sectional regression of the two-factor cash flow model. ${ }^{31}$ The characteristics chosen are size and book-to-market ratio after log transformation. The regression coefficients and t-values are computed using Fama-MacBeth regressions. I find that the portfolio characteristics are not significant in the cross sectional regressions of the two-factor cash flow model (Panel C), so model misspecification is unlikely. In contrast, both size and book-to-market ratio are significant in the cross-sectional regressions for the commonly used Fama-French three-factor model, indicating possible model misspecification (Panel D), consistent with previous research. ${ }^{32}$ Finally, I put the Fama-French three factors and the two cash flow factors in one cross-sectional regression as a "horse race," the two cash flow factors seem to drive out the Fama-French factors.

Finally, I also test the two-factor cash flow model on book-to-market and size double-sorted portfolios, a method that provides more statistical power. From 1964 to 1995, the portfolios are formed in June and held for 12 years. I conduct a smaller $3 \times 3$ sort since both Cov and Dur are better estimated on larger portfolios. The descriptive statistics including the point estimates of cash flow covariance and duration risks are provided in Panel A of Table 8. As before, value (small) stocks have higher cash flow covariance measures than growth (large) stocks in general except small growth portfolio. Also as before, with the exception of a small growth portfolio, growth stocks have higher cash flow duration measures than value stocks. Small stocks again have lower durations than large stocks except in value group. If I estimate the regression (1) on all nine portfolios, the results do not turn out as favorably: the adjusted R-square is only 0.254 and the coefficient on Cov $\times$ Dur has the wrong sign, which seems to indicates the failure of the two-factor cash flow model on the double-sorted portfolios. A closer look shows that this unfavorable performance is primarily driven by the small growth portfolio. If I exclude that portfolio and run the regression on the remaining eight portfolios, the results improve significantly: R-square increases to 0.817 and both factors are significant with the right sign on the coefficient $C o v \times D u r$. Figure 6 contains a graphic representation of the these results. The two-factor cash flow model fits the excess returns on double-sorted portfolios reasonably well if the small growth portfolio is excluded. The small growth portfolio, troublesome to most asset pricing models, is ever more so for the two-factor cash

\footnotetext{
${ }^{31}$ See Berk (1995), Daniel and Titman (1997), Jagannathan and Wang (1998) and Lettau and Ludvigson (2001) for discussions of using portfolio characteristics to detect model misspecification.

${ }^{32}$ See Daniel and Titman (1997) and Lettau and Ludvigson (2001) for an example.
} 
flow model. This may be due to two reasons. First, the mean-reverting cash flow share assumption may be violated for the small growth stocks. Second, the approximation error in the two-factor cash flow model may be particularly large for small growth stocks.

To summarize the results thus far, the cash flow models, estimated using pure cash flow data, are able to sufficiently explain the cross-sectional variation of expected excess returns of BM sorted and size sorted portfolios. An interaction term involving cash flow duration captured using the variable Dur (not dividend yield $-D / P$ ) has additional explanatory power on top of the commonly studied covariance risk. A two-factor cash flow model accounting for the cash flow duration perform better than most of the commonly used models estimated using returns; furthermore, it is not likely to suffer from model misspecification. The two-factor cash flow model also explains the expected excess returns of BM and size double sorted portfolios if the small growth portfolio is excluded. I also verify that these results remain the same if I replace Dur by its ex-ante measure $\widehat{D u r}$.

\section{F. Does cash flow duration alone explain value premium?}

Two interesting empirical patterns occur in Table 3 and 4. First, cash flow duration seems inversely related to cash flow covariance for the BM-sorted and size-sorted portfolios. This pattern offers a simple solution to the duration risk puzzle. Dechow, Sloan and Soliman (2004) find stocks with high duration risk to earn lower expected returns. This finding is somewhat counter-intuitive since one would expect higher risk to be compensated by higher returns. Their finding may be explained by the empirical inverse relationship between cash flow duration and covariance : high-cash-flowduration stocks earn lower returns since they happen to have low cash flow covariances at the same time.

Second, book-to-market ratio seems inversely related to cash flow duration. This pattern should not at all surprise us. As pointed out by Lintner (1975) and Santa-Clara (2004), any measure of cash flow duration will be related to book-to-market ratio simply as a result of accounting identities. Making use of the accounting clean surplus identity and return-dividend-price relation, Vuolteenaho (2002a) show that the log book-to-market ratio $\left(\theta_{t}\right)$ can be approximated as:

$$
\theta_{t}=\sum_{j=0}^{\infty} \rho^{j} r_{t+j+1}-\sum_{j=0}^{\infty} \rho^{j} e_{t+j+1},
$$

where $r$ denotes log returns. Substituting the early definition of $\Sigma_{t}^{e}$, (14) becomes:

$$
\theta_{t}=\sum_{j=0}^{\infty} \rho^{j} r_{t+j+1}-\Sigma_{t}^{e}
$$


Compare (15) against the cash flow duration measure (9), we can immediately see that an increase in $\Sigma_{t}^{e}$ will increase cash flow duration measure but decrease book-to-market ratio. Therefore, cash flow duration is negatively correlated with book-to-market ratio. Lettau and Wachter (2004) study an economy in which stocks are only distinguished by the timing of their cash flows. In such an economy, they show that stocks with cash flows weighted more to the future (high duration) have low price ratios (book-to-market ratio for example) and earn low return. Therefore, cash flow duration can potentially explain value premium. My results, on the topical level, seem to support their hypothesis since value stock indeed has lower duration than growth stock. An unreported regression shows that a cash flow model with cash flow duration explains the cross-sectional variation in expected excess returns of BM sorted portfolios almost as well as a cash flow model with cash flow covariance. However, we will require further analysis to answer a more interesting question: can the cash flow duration alone can explain value premium? If the cash flow duration alone perfectly explains value premium, we would expect further sorting on book-to-market ratio to generate no spread in returns once we control for cash flow duration.

To control for cash flow duration, I first sort all stocks according to the "ex-ante" cash flow duration measure- $\widehat{\operatorname{Dur}}_{t}$ into three groups: Low Duration, Medium Duration and High Duration. Within each group, I further sort stocks according to BM into three subgroups. To make sure that such portfolio construction is implementable, at each year, I re-estimate (13) using data from 1965 through the current year, so the duration measure $\widehat{\operatorname{Dur}}_{t}$ is only computed using information available at year $t$. For this reason, I start my portfolio construction at year 1975 so I have at least 5 year data ${ }^{33}$ to estimate the duration measure for year 1975. Table 9 contains the results of the double sort. Since BM and duration are negatively correlated, sorting on BM within each duration group will likely induce a spread in cash flow durations. This is particularly true for stocks in Low Duration groups in which low BM stocks have a cash flow duration measure of 1.28 but high BM stocks have a cash flow duration measure of only -0.05. In contrast, the spread is much smaller for stocks in Medium and High Duration groups. Therefore, if cash flow duration alone explains the value premium, I should expect that further sorting on BM generates no significant spread on returns for these stocks with similar cash flow duration. However, this is not the case. Value stocks still earn much higher returns than growth stocks in the same cash flow duration group. The difference can be explained by the cash flow covariance risk - value stocks have indeed higher cash flow covariance risk than growth stocks. This last finding is consistent with the two-factor cash flow model, but not with the hypothesis that duration risk alone explains value premium.

\footnotetext{
${ }^{33}$ The 5 year is from 1965-1969, as I need additional five year to compute $\overline{\Sigma_{t}^{e}}$ on the left hand side of equation (13).
} 


\section{Conclusion}

This paper links the cross-sectional variation in assets' returns directly to the cross-sectional variation in their fundamental cash flow characteristics. The dynamics of the cash flow stream of an asset are summarized using two characteristics: Cov (covariance - how cash flow varies with aggregate consumption) and Dur (duration - whether cash flow occurs further in the future). In a general consumption-based asset pricing framework, I denote the price and expected (excess) return of the cash flow stream as functions of Cov and Dur. I then show that a large portion of cross-sectional variation in expected excess return can be explained by a two-factor cash flow model with the two factors being Cov and Cov $\times$ Dur, respectively.

Empirically, the cash flow covariance and duration are estimated using only consumption and accounting data for 10 book-to-market sorted and 10 size-sorted portfolios. I show that both characteristics are important in explaining the cross-sectional variation in risk premia. While the cash flow covariance has a first-order impact on the cross-sectional variation of risk premia, the cash flow duration also provides additional explanatory power through a second-order interaction term and its impact on the risk premium depends on the sign and magnitude of the cash flow covariance. Given two assets with very different cash flow durations (such as value and growth stock portfolios), it is therefore important to account for cash flow duration in explaining their return difference. I show that a two-factor cash flow model incorporating both cash flow characteristics is able to explain $82 \%$ of the cross-sectional variation in risk premia in 20 size or book-to-market sorted stock portfolios. In addition, the two-factor cash flow model compares favorably against common benchmark models.

Cash flow duration and covariance are inversely related for the 20 portfolios, which suggests a simple solution to the duration risk puzzle: stocks with high cash flow duration may earn lower expected return simply because they happen to have low cash flow covariance at the same time. Nevertheless, I find cash flow duration alone cannot explain the value premium. Value stocks still earn much higher returns than growth stock in the same duration group. The difference can be explained by the cash flow covariance risk - value stocks have indeed higher cash flow covariances than growth stock. All of this is consistent with the two-factor cash flow model where cash flow covariance has a first-order impact on the cross-sectional variation of risk premia.

The recent paper by Santos and Veronesi (2005) simultaneously matches both the time-series properties of the market portfolio and the value premium in a habit persistence, general equilibrium model. This paper, however, focuses on the cross-section implications of an asset's cash flow characteristics rather than their time-series implications. It does not explicitly incorporate the model-implied time-series restrictions in the cross-sectional regression, because that requires taking 
positions on the specific forms of investor's preference and the stochastic process of the aggregate consumption, narrowing the scope of the model. The economic specification in Bansal and Yaron (2004) is a good place to start as it has been proven to justify many time-series properties of the financial market. It will be interesting to examine whether parameters of such economy, calibrated to the time-series properties of the financial market, can simultaneously explain the size of the risk premium found in the cross-sectional analysis.

\section{References}

[1] Abel, A. (1990): "Asset prices under habit formation and catching up with the Joneses," American Economic Review, Vol 80, 38-42.

[2] Abel, A. (1999): "Risk premia and term premia in general equilibrium," Journal of Monetary Economics, Vol. 43, 3-33.

[3] Bansal, R. and A. Yaron (2002): "Risk for the long run: A potential resolution of asset pricing puzzles," NBER Working Paper.

[4] Bansal, R. and A. Yaron (2004): "Risk for the long run: A potential resolution of asset pricing puzzles," Journal of Finance, Vol 59, 1481-1509.

[5] Bansal, R., R.F. Dittmar and D. Kiku (2005): “ Long run risks and equity returns," Working Paper.

[6] Bansal, R., R.F. Dittmar and C.T. Lundblad (2002): "Consumption, dividends, and the crosssection of equity returns," Working Paper.

[7] Bansal, R., R.F. Dittmar and C.T. Lundblad (2005): "Consumption, dividends, and the crosssection of equity returns," Journal of Finance, Vol. 60, 1639-1672.

[8] Breeden, D. (1979): "An intertemporal asset pricing model with stochastic consumption and investment opportunities," Journal of Financial Economics, Vol 7, 265-296.

[9] Breeden, D., M. Gibbons and R. Litzenberger (1989): "Empirical tests of the consumptionoriented CAPM," Journal of Finance, Vol 44, 231-262.

[10] Brennan, M., A. Wang and Y. Xia (2004): "Estimation and test of a simple model of intertemporal asset pricing," Journal of Finance, Vol 59, 1743-1775.

[11] Brennan, M. and Y. Xia (2003): "Risk and valuation under an intertemporal capital asset pricing model," Journal of Business, forthcoming. 
[12] Campbell, J. (1993): "Intertemporal asset pricing without consumption data," American Economic Review, Vol 83, 487-512.

[13] Campbell, J. (1996): "Understanding risk and return," Journal of Political Economy, Vol 104, 298-345.

[14] Campbell, J. (2000): "Asset pricing at the millennium," Journal of Finance, Vol 55, 15151567.

[15] Campbell, J. and J. Cochrane (1999): "By force of habit: A consumption-based explanation of aggregate stock market behavior," Journal of Political Economy, Vol 107, 205-251.

[16] Campbell, J. and J. Mei (1993): "Where do betas come from? Asset price dynamics and the sources of systematic risk," Review of Financial Studies, Vol 6, 567-592.

[17] Campbell, J., C. Polk and T. Vuolteenaho (2003): "Growth or Glamour," Working Paper.

[18] Campbell, J. and R.J. Shiller (1988): "The dividend-price ratio and expectations of future dividends and discount factors," Review of Financial Studies, Vol 1, 195-228.

[19] Campbell, J. and T. Vuolteenaho (2004): "Bad beta, good beta," American Economic Review, Vol 94, 1249-1275.

[20] Chan, K., K.C. Chan, N. Jegadeesh and J. Lakonishok (2001): "Earnings quality and stock returns," NBER Working Paper 8308, Cambridge, MA

[21] Cochrane, J. (2001): “Asset pricing," Princeton University Press.

[22] Cohen R.B., C. Polk and T. Vuolteenaho (2003a): "The value spread," Journal of Finance, Vol 58, 609-641.

[23] Cohen R.B., C. Polk and T. Vuolteenaho (2003b): "The price is (almost) right," Working Paper.

[24] Connor, G. and R.A. Korajczyk (1989): "An intertemporal equilibrium beta pricing model," Review of Financial Studies, Vol 2, 373-392.

[25] Cornell, B. (1999): "Risk, duration, and capital budgeting: new evidence on some old questions," Journal of Business, Vol 72, 183-200.

[26] Cornell, B. (2000): "Equity duration, growth options, and asset pricing," Journal of Portfolio Management, Vol 26, 105-111. 
[27] Da, Z., P. Gao and Y. Wang (2004): "A note on CRSP and COMPUSTAT linking procedure," Working Paper.

[28] Daniel, K. and D. Marshall (2004): "Consumption-based modeling of long-horizon returns," Working Paper.

[29] Daniel, K. and S. Titman (1997): "Evidence on the characteristics of cross sectional variation in stock returns," Journal of Finance, Vol 52, 1-33.

[30] Damodaran, A. (2003): "Investment valuation," Second edition.

[31] Dechow, P., R.G. Sloan and M.T. Soliman (2004): "Implied equity duration: a new measure of equity risk," Review of Accounting Studies, Vol 9, 197-228.

[32] Epstein, L. and S. Zin (1989): "Substitution, risk aversion, and the temporal behavior of consumption and asset returns: A theoretical framework," Econometrica, Vol 57, 937-969.

[33] Epstein, L. and S. Zin (1991): "Substitution, risk aversion, and the temporal behavior of consumption and asset returns: An empirical analysis," Journal of Political Economy, Vol 99, 263-286.

[34] Fama, E. and K. French (1992): "The cross-section of expected stock returns," Journal of Finance, Vol 47, 427-465.

[35] Fama, E. and K. French (1993): "Common risk factors in the returns on stocks and bonds," Journal of Financial Economics, Vol 33, 3-56.

[36] Fama, E. and K. French (1996): “Multifactor explanations of asset pricing anomalies," Journal of Finance, Vol 51, 55-84.

[37] Grullon, G. and R. Michaely (2002): "Dividends, share repurchases, and the substitution hypothesis," Journal of Finance, Vol 57, 1649-1684.

[38] Hansen, L. P., J. Heaton and N. Li (2005): "Consumption strikes back?: Measuring long-run risk", Working Paper.

[39] Hansen, L. P. and K. J. Singleton (1983): "Stochastic consumption, risk aversion, and the temporal behavior of asset returns," Journal of Political Economy, Vol. 91, 249-265.

[40] Jagannathan, R. and S. Viswanathan (1988): "Linear factor pricing, term structure of interest rates and the small firm anomaly," Working paper, Northwestern University.

[41] Jagannathan, R. and Y. Wang (2005): "Lazy investors, discretionary consumption, and the cross section of stock returns", Working Paper. 
[42] Jagannathan, R. and Z. Wang (1996): "The conditional CAPM and the cross-section of expected returns," Journal of Finance, Vol 51, 3-53.

[43] Jagannathan, R. and Z. Wang (1998): "An asymptotic theory for estimating beta-pricing models using cross-sectional regression," Journal of Finance, Vol 53, 1285-1309.

[44] Jones, J.J. (1991): "Earnings management during import relief investigation," Journal of Accounting Research, Vol 29, 193 - 228.

[45] Lakonishok, J., A. Shleifer and R.W. Vishny (1994): "Contrarian investment, extrapolation, and risk," Journal of Finance, Vol 49, 1541-1578.

[46] Lettau, M. and S. Ludvigson (2001): "Consumption, aggregate wealth, and expected stock returns," Journal of Finance, Vol 56, 815-849.

[47] Lettau, M. and S. Ludvigson (2001): "Resurrecting the (C)CAPM: A cross-sectional test when risk premia are time-varying," Journal of Political Economy, Vol 109, 1238-1287.

[48] Longstaff, F.A. and M. Piazzesi (2004): "Corporate earnings and the equity premium," Journal of Financial Economics, Vol 74, 401-421.

[49] Lettau, M. and J.A. Wachter (2004): "Why is long-horizon equity less risky? A duration-based explanation of the value premium," Working Paper.

[50] Lintner, J. (1965): "Security prices, risk , and maximal gains from diversification," Journal of Finance, Vol 20, 587-615.

[51] Lintner, J. (1975): “Inflation and security returns," Journal of Finance, Vol 30, 259-280.

[52] Lucas, R. (1978): “Assets prices in an exchange economy," Econometrica, Vol 46, 1429-1445.

[53] Mehra, R. and E. Prescott (1985): "The equity premium: A puzzle," Journal of Monetary Economics, Vol 15, 145-161.

[54] Menzly, L., T. Santos and P. Veronesi (2004): "Understanding predictability," Journal of Political Economy, Vol 112, 1-47.

[55] Merton, R.C. (1973): “An intertemporal capital asset pricing model,".Econometrica, Vol 41, $867-887$.

[56] Parker, J. and C. Julliard (2005): "Consumption risk and the cross-section of expected returns," Journal of Political Economy, Vol 113, 185-222. 
[57] Roll, R. (1977): "A critique of the asset pricing theory's test: Part 1: On past and potential testability of the theory," Journal of Financial Economics, Vol 4, 129-176.

[58] Rubinstein, Mark. (1976): "The valuation of uncertain income streams and the pricing of options," Bell Journal of Economics and Management Science, Vol 7, 407- 425.

[59] Santa-Clara, P. (2004): "Discussion of 'implied equity duration: a new measure of equity risk'," Review of Accounting Studies, Vol 9, 229-231.

[60] Santos, T. and P. Veronesi (2004): "Conditional betas," Working Paper.

[61] Santos, T. and P. Veronesi (2005): "Cash-flow risk, discount risk, and the value premium," Working Paper.

[62] Sharpe, W. (1964): "Capital asset prices: a theory of market equilibrium under conditions of risk," Journal of Finance, Vol 19, 425-442.

[63] Teoh S. H., I. Welch and T.J. Wong (1998a): "Earnings management and the long-run market performance of initial public offerings," Journal of Finance, Vol 53, 1935-1974.

[64] Teoh S. H., I. Welch and T.J. Wong (1998b): "Earnings management and the post-issue underperformance of seasoned equity offerings," Journal of Financial Economics, Vol 50, 6399

[65] Vuolteenaho, T. (2002a): "Understanding the aggregate book-to-market ratio," Working Paper.

[66] Vuolteenaho, T. (2002b): "What drives firm-level stock returns," Journal of Finance, Vol 57, 233-264. 


\section{Appendix 1: Proofs}

\section{A1.1: Proof of Lemma 1}

For $\psi \neq 1, \log$ stochastic discount factor for Epstein and Zin utility can be expressed as:

$$
m_{t+1}=\theta\left[\log \delta-\frac{1}{\psi} \Delta c_{t+1}\right]+(\theta-1) r_{a, t+1}
$$

where $\theta=(1-\gamma) /(1-1 / \psi) ; \gamma$ and $\psi$ denote coefficient of risk aversion and elasticity of intertemporal substitution respectively; $\delta$ is the time discount factor and $r_{a, t+1}$ denotes return on the aggregate wealth portfolio.

Use log-linear approximation to write:

$$
\begin{aligned}
r_{a, t+1} & =\kappa_{0}+\kappa_{1} x_{t+1}-x_{t}+c_{t+1}-c_{t}, \\
\kappa_{1} & =\frac{\exp (\bar{x})}{1+\exp (\bar{x})} \\
\kappa_{0} & =\log [1+\exp (\bar{x})]-\kappa_{1} \bar{x}
\end{aligned}
$$

where $x_{t}$ is the $\log$ wealth to consumption ratio $\left(\log \frac{W_{t}-C_{t}}{C_{t}}\right)$ at time $t$ and $\bar{x}$ is its time-series average.

The definition of stochastic discount factor implies:

$$
E_{t}\left[\exp \left(m_{t+1}+r_{a, t+1}\right)\right]=1
$$

I conjecture that $x_{t+1}$ can also be expressed as:

$$
x_{t+1}=\mu_{x}+\phi^{x}(L) w_{t+1} .
$$

Then (16) implies:

$$
\left\{\begin{array}{c}
\log \delta-\frac{1}{\psi}\left[\mu_{c}+\phi^{c}(L) w_{t+1}-\phi^{c}(0) w_{t+1}\right]+\kappa_{0}+\kappa_{1} \mu_{x}-\mu_{x} \\
+\kappa_{1}\left[\phi^{x}(L)-\phi^{x}(0)\right] w_{t+1}-\phi^{x}(L) w_{t}+\mu_{c}+\left[\phi^{c}(L)-\phi^{c}(0)\right] w_{t+1}+ \\
+\frac{1}{2} \theta\left[\left(1-\frac{1}{\psi}\right) \phi^{c}(0)+\kappa_{1} \phi^{x}(0)\right] \cdot\left[\left(1-\frac{1}{\psi}\right) \phi^{c}(0)+\kappa_{1} \phi^{x}(0)\right]
\end{array}\right\}=0 .
$$

Then,

$$
\left(1-\frac{1}{\psi}\right)\left[\phi^{c}(L)-\phi^{c}(0)\right]+\kappa_{1}\left[\phi^{x}(L)-\phi^{x}(0)\right]=\phi^{x}(L) L,
$$

which should still hold when we replace $L$ by $\kappa_{1}$; therefore: 


$$
\left(1-\frac{1}{\psi}\right)\left[\phi^{c}\left(\kappa_{1}\right)-\phi^{c}(0)\right]=\kappa_{1} \phi^{x}(0) .
$$

(17) also implies:

$$
\left\{\begin{array}{c}
\log \delta+\left(1-\frac{1}{\psi}\right) \mu_{c}+\kappa_{0}+\kappa_{1} \mu_{x}-\mu_{x} \\
+\frac{1}{2} \theta\left[\left(1-\frac{1}{\psi}\right) \phi^{c}(0)+\kappa_{1} \phi^{x}(0)\right] \cdot\left[\left(1-\frac{1}{\psi}\right) \phi^{c}(0)+\kappa_{1} \phi^{x}(0)\right]
\end{array}\right\}=0 .
$$

(18) and (19) together provide a solution for $\mu_{x}$ :

$$
\mu_{x}=\frac{\log \delta+\left(1-\frac{1}{\psi}\right) \mu_{c}+\kappa_{0}+\frac{1}{2} \theta\left(1-\frac{1}{\psi}\right)^{2} \phi^{c}\left(\kappa_{1}\right) \cdot \phi^{c}\left(\kappa_{1}\right)}{1-\kappa_{1}} .
$$

Some algebra then shows:

$$
\begin{aligned}
m_{t+1} & =\mu_{m}+\phi^{m}(L) w_{t+1} \\
\mu_{m} & =\log \delta-\frac{1}{\psi} \mu_{c}-\frac{1}{2}\left(\frac{1}{\psi}-\gamma\right)(1-\gamma) \phi^{c}\left(\kappa_{1}\right) \cdot \phi^{c}\left(\kappa_{1}\right), \\
\phi^{m}(L) & =\left[-\frac{1}{\psi} \phi^{c}(L)+\left(\frac{1}{\psi}-\gamma\right) \phi^{c}\left(\kappa_{1}\right)\right] .
\end{aligned}
$$

In particular, if $\psi=1$, then $x_{t}=\bar{x}=\log \left(\frac{\delta}{1-\delta}\right)$, and,

$$
\kappa_{1}=\delta
$$

We have the same expression as in Hansen, Heaton and Li (2004). The approximation holds exactly.

Q.E.D.

\section{A1.2: Proof of Proposition 1}

To compute the price of equity strip $P_{n, t}^{i}$, I make use of the fact:

$$
E_{t}\left[M_{t+1} P_{n-1, t+1}^{i}\right]=P_{n, t}^{i},
$$

which implies:

$$
E_{t}\left[M_{t+1} \frac{D_{t+1}^{i}}{D_{t}^{i}} \frac{P_{n-1, t+1}^{i}}{D_{t+1}^{i}}\right]=\frac{P_{n, t}^{i}}{D_{t}^{i}}
$$


Conjecture that:

$$
\frac{P_{n, t}^{i}}{D_{t}^{i}}=\exp \left[A^{i}(n)+B(n) z_{t}^{i}+C^{n}(L) w_{t}\right],
$$

where $C^{n-1}(L)$ is also a lag operator. Since $P_{0, t}^{i}=D_{t}^{i}$, we have $A^{i}(0)=B(0)=0$ and $C^{0}(L)$ contains zero everywhere.

We have:

$$
\begin{aligned}
& E_{t}\left[\exp \left\{m_{t+1}+\Delta s_{t+1}^{i}+\Delta c_{t+1}+A^{i}(n-1)+B(n-1) z_{t+1}^{i}+C^{n-1}(L) w_{t+1}\right\}\right] \\
= & \exp \left\{A^{i}(n)+B(n) z_{t}^{i}+C^{n}(L) w_{t}\right\} .
\end{aligned}
$$

Under Assumption 1 to 3, evaluate the expectation and match terms involving $z_{t}^{i}$, we have:

$$
(1-\phi)+B(n-1) \phi=B(n) .
$$

Solving the difference equation with initial condition $B(0)=0$, we have:

$$
B(n)=1-\phi^{n}
$$

Matching constants, we have:

$$
A^{i}(n)=A^{i}(n-1)+\mu_{m}+\mu_{c}+\frac{1}{2}\left\|\left(1+\phi^{n-1} \lambda^{i}\right) \phi^{c}(0)+\phi^{m}(0)\right\|^{2}+\frac{1}{2}\left(\phi^{n-1} \sigma_{\varepsilon}\right)^{2},
$$

where $\|a\|=\sqrt{a \cdot a}$ and $\sigma_{\varepsilon}$ is the standard deviation of $\varepsilon$.

Matching $w$, we have:

$$
\phi^{m}(L)-\phi^{m}(0)+\phi^{c}(L)-\phi^{c}(0)+C^{n-1}(L)-C^{n-1}(0)=C^{n}(L) L .
$$

Therefore, $A^{i}(n)$ and $C^{n}(L)$ can also be solved iteratively given the initial condition.

Define the return on individual cash flow claim as:

$$
\begin{aligned}
R_{n, t+1}^{i} & =\frac{P_{n-1, t+1}^{i}}{P_{n, t}^{i}} \\
& =\frac{P_{n-1, t+1}^{i} / D_{t+1}^{i}}{P_{n, t}^{i} / D_{t}^{i}} \frac{D_{t+1}^{i}}{D_{t}^{i}} .
\end{aligned}
$$

Take the log, 


$$
\begin{aligned}
r_{n, t+1}^{i}= & A^{i}(n-1)-A^{i}(n)+B(n-1) z_{t+1}^{i}-B(n) z_{t}^{i} \\
& +C^{n-1}(L) w_{t+1}-C^{n}(L) w_{t}+\Delta s_{t+1}^{i}+\Delta c_{t+1} .
\end{aligned}
$$

The one period innovation is:

$$
r_{n, t+1}^{i}-E_{t}\left[r_{n, t+1}^{i}\right]=\left(1+\phi^{n-1} \lambda^{i}\right) \phi^{c}(0) w_{t+1}+C^{n-1}(0) w_{t+1}+\phi^{n-1} \varepsilon_{t+1}^{i} .
$$

Therefore,

$$
\log E_{t}\left[R_{n, t+1}^{i} / R f_{t}\right]=-\left(1+\phi^{n-1} \lambda^{i}\right) \phi^{c}(0) \cdot \phi^{m}(0)-C^{n-1}(0) \cdot \phi^{m}(0)
$$

Q.E.D.

\section{Appendix 2: From fundamental cash flow characteristics to return betas}

Assumption 4: Log cash flow growth for an individual asset can be written as:

$$
\Delta d_{t+1}^{i}=\mu_{d}^{i}+\phi^{d, i}(L) w_{t+1}+\pi^{i}(L) \varepsilon_{t+1},
$$

where $\phi^{d, i}(L)$ and $\pi^{i}(L)$ are lag operators similar to $\phi^{c}(L)$ and $\varepsilon$ is independent of $w . \phi^{d, i}(L)$ can be thought of as cash flow loadings on consumption growth innovations. $\pi^{i}(L) \varepsilon_{t+1}$ are the innovations in cash flow orthogonal to consumption growth innovations.

The cash flow structure assumed in Assumption 4 is very general. It includes the mean-reverting cash flow share structure, since under Assumption 3:

$$
s_{t+1}^{i}=\bar{s}^{i}+(1-\phi L)^{-1} \lambda^{i} \phi^{c}(0) w_{t+1}+(1-\phi L)^{-1} \varepsilon_{t+1}^{i} .
$$

Therefore:

$$
s_{t+1}^{i}-s_{t}^{i}=(1-\phi L)^{-1}(1-L) \lambda^{i} \phi^{c}(0) w_{t+1}+(1-\phi L)^{-1}(1-L) \varepsilon_{t+1}^{i},
$$

and,

$$
d_{t+1}^{i}-d_{t}^{i}=s_{t+1}^{i}-s_{t}^{i}+c_{t+1}-c_{t}
$$

This implies: 


$$
\begin{aligned}
\phi^{d, i}(L) & =(1-\phi L)^{-1}(1-L) \lambda^{i} \phi^{c}(0)+\phi^{c}(L), \\
\pi^{i}(L) & =(1-\phi L)^{-1}(1-L) .
\end{aligned}
$$

Given the general cash flow structure, we can write out the stock return using log-linear approximation.

Proposition 2: Assumption 1, 2 and 4 imply log return can be approximated as:

$$
r_{t+1}^{i}=E_{t}\left[r_{t+1}^{i}\right]+\beta^{i} w_{t+1}+\varkappa^{i} \varepsilon_{t+1}
$$

where

$$
\beta^{i}=\phi^{m}\left(\kappa_{1}^{i}\right)-\phi^{m}(0)+\phi^{d, i}\left(\kappa_{1}^{i}\right)
$$

and $\kappa_{1}^{i}$ is a constant defined below.

Proof: The proof is similar to that of Lemma 1. Again, use log-linear approximation to write:

$$
\begin{aligned}
r_{t+1}^{i} & =\kappa_{0}^{i}+\kappa_{1}^{i} x_{t+1}^{i}-x_{t}^{i}+d_{t+1}^{i}-d_{t}^{i} \\
\kappa_{1}^{i} & =\frac{\exp \left(\bar{x}^{i}\right)}{1+\exp \left(\bar{x}^{i}\right)} \\
\kappa_{0}^{i} & =\log \left[1+\exp \left(\bar{x}^{i}\right)\right]-\kappa_{1}^{i} \bar{x}^{i} .
\end{aligned}
$$

where $x_{t}^{i}$ is the $\log$ price to cash flow ratio $\left(\log \frac{P_{t}}{D_{t}}\right)$ at time $t$ and $\bar{x}^{i}$ is its time-series average. Conjecture $x_{t+1}^{i}=\mu_{x}^{i}+\phi^{i, x}(L) w_{t+1}+\phi^{i, \varepsilon}(L) \varepsilon_{t+1}$ and use the relation:

$$
E_{t}\left[\exp \left(m_{t+1}+r_{t+1}^{i}\right)\right]=1
$$

we have,

$$
\left\{\begin{array}{c}
\mu_{m}+\left[\phi^{m}(L)-\phi^{m}(0)\right] w_{t+1}+\kappa_{0}^{i}+\kappa_{1}^{i} \mu_{x}^{i}-\mu_{x}^{i}+\kappa_{1}^{i}\left[\phi^{i, x}(L)-\phi^{i, x}(0)\right] w_{t+1}-\phi^{i, x}(L) w_{t}+ \\
\kappa_{1}^{i}\left[\phi^{i, \varepsilon}(L)-\phi^{i, \varepsilon}(L)\right] \varepsilon_{t+1}-\phi^{i, \varepsilon}(L) \varepsilon_{t}+\mu_{d}^{i}+\left[\phi^{d, i}(L)-\phi^{d, i}(L)\right] w_{t+1}+\left[\pi^{i}(L)-\pi^{i}(0)\right] \varepsilon_{t+1}+ \\
\frac{1}{2}\left[\phi^{m}(0)+\kappa_{1}^{i} \phi^{i, x}(0)+\phi^{d, i}(0)\right] \cdot\left[\phi^{m}(0)+\kappa_{1}^{i} \phi^{i, x}(0)+\phi^{d, i}(0)\right]+ \\
\frac{1}{2}\left(\sigma_{\varepsilon}^{i}\right)^{2}\left[\kappa_{1}^{i} \phi^{i, \varepsilon}(0)+\pi^{i}(0)\right] \cdot\left[\kappa_{1}^{i} \phi^{i, \varepsilon}(0)+\pi^{i}(0)\right]
\end{array}\right\}=0 .
$$

Solve for $\mu_{x}^{i}, \phi^{i, x}(L)$ and $\phi^{i, \varepsilon}(L)$ by matching terms with $w$ and terms with $\varepsilon$. Then, 


$$
\begin{aligned}
r_{t+1}^{i} & =E_{t}\left[r_{t+1}^{i}\right]+\beta^{i} w_{t+1}+\varkappa^{i} \varepsilon_{t+1}, \text { where } \\
\beta^{i} & =\kappa_{1}^{i} \phi^{i, x}(0)+\phi^{d, i}(0) \\
& =\phi^{m}\left(\kappa_{1}^{i}\right)-\phi^{m}(0)+\phi^{d, i}\left(\kappa_{1}^{i}\right), \\
\varkappa^{i} & =\kappa_{1}^{i} \phi^{i, \varepsilon}(0)+\pi^{i}(0)=\pi^{i}\left(\kappa_{1}^{i}\right) .
\end{aligned}
$$

Under the Epstein and Zin utility, results in Appendix 1 imply:

$$
\beta^{i}=-\frac{1}{\psi}\left[\phi^{c}\left(\kappa_{1}^{i}\right)-\phi^{c}(0)\right]+\phi^{d, i}\left(\kappa_{1}^{i}\right) .
$$

Q.E.D.

It is relatively easy to show the cash flow specification of Bansal, Dittmar and Lundblad (2002) as a special case of Proposition 2. Elements in $\beta^{i}$ can be regarded as factor loadings or betas. Proposition 2 therefore directly relates betas to the preference parameters, as reflected in $\phi^{m}\left(\kappa_{1}^{i}\right)-\phi^{m}(0)$, and fundamental asset cash flow characteristics, as reflected in $\phi^{d, i}\left(\kappa_{1}^{i}\right)$. The crosssection of risk premia is then determined by the inner product of beta and factor risk premium (ignoring the convexity adjustment term):

$$
E_{t}\left[r_{t+1}^{i}-r f_{t}\right]+\frac{\sigma_{t}^{2}\left[r_{t+1}^{i}\right]}{2}=-\beta^{i} \cdot \phi^{m}(0)
$$

The standard consumption beta is a scalar, defined as proportional to the covariance between return and contemporaneous innovation in consumption growth:

$$
\begin{aligned}
\beta_{c}^{i} & \propto \operatorname{cov}\left(r_{t+1}^{i}, \Delta c_{t+1}-E_{t}\left[\Delta c_{t+1}\right]\right) \\
& =\beta^{i} \cdot \phi^{c}(0) .
\end{aligned}
$$

$\beta_{c}^{i}$ can be identified (up to a scaling factor) by regressing return on consumption growth. Estimating $\beta_{c}^{i}$ in this way using short-term consumption growth, Breeden, Gibbons and Litzenberger (1989) shows that $\beta_{c}^{i}$ does poorly in explaining cross-sectional variation in expected excess returns. There are several possible reasons behind this poor performance. First, short-term consumption growth is problematic due to measurement error, consumption commitment or delayed response. Recent studies show cross-sectional variation in expected excess returns can be explained if consumption growth over longer horizon is used (c.f. Daniel and Marshall (2004), Parker and Juliard (2004) and Jagannathan and Wang (2005)). Second, $\beta_{c}^{i}$ can be viewed as a linear combination 
of true factor betas contained in $\beta^{i}$. In a multi-factor pricing framework, although $\beta^{i}$ is able to explain the cross-section of risk premia, $\beta_{c}^{i}$ may not be. This point has been made in Bansal, Dittmar and Lundblad (2005).

To link $\beta^{i}$ to asset's cash flow risk (covariance and duration in particular) more explicitly, I consider a return decomposition similar to Campbell and Mei (1993) and Campbell, Polk and Vuolteenaho (2003). I decompose return on individual stock into a component $\left(N_{C F i, t+1}\right)$, related to cash flow news, and a component $\left(N_{D R i, t+1}\right)$, related to discount rate news, as:

$$
\begin{aligned}
r_{t+1}^{i}-E_{t}\left[r_{t+1}^{i}\right] & =N_{C F i, t+1}-N_{D R i, t+1}, \text { where } \\
N_{C F i, t+1} & =\left(E_{t+1}-E_{t}\right) \sum_{j=0}^{\infty}\left(\kappa_{1}^{i}\right)^{j} \Delta d_{t+1+j}^{i}, \\
N_{D R i, t+1} & =\left(E_{t+1}-E_{t}\right) \sum_{j=1}^{\infty}\left(\kappa_{1}^{i}\right)^{j} r_{t+1+j}^{i} .
\end{aligned}
$$

We may have the impression that $N_{C F i, t+1}$ is related to cash flow covariance risk and that $N_{D R i, t+1}$ is related to cash flow duration. Using notations in the general framework, we can easily show:

$$
\begin{aligned}
\beta^{i} & =\beta_{C F}^{i}+\beta_{D R}^{i}, \\
\beta_{C F}^{i} & =\phi^{d, i}\left(\kappa_{1}^{i}\right), \\
\beta_{D R}^{i} & =\phi^{m}\left(\kappa_{1}^{i}\right)-\phi^{m}(0) .
\end{aligned}
$$

$\beta_{C F}^{i}$ and $\beta_{D R}^{i}$ come from the cash flow news and discount rate news, respectively. $\phi^{d, i}(L)$ contains firms' cash flow loadings on consumption growth innovations. $\beta_{C F}^{i}$ measures the sum of those discounted loadings with the discount factor as $\kappa_{1}^{i}$, therefore, $\beta_{C F}^{i}$ in fact measures covariance risk to a large extent. Moreover, $\kappa_{1}^{i}$, being a function of average dividend yield, is related to both cash flow covariance and duration, so $\beta_{C F}^{i}$ also captures cash flow duration as well. $\beta_{D R}^{i}$ varies across stocks because of the $\kappa_{1}^{i}$ term and thus captures both risks, just as $\beta_{C F}^{i}$. This beta decomposition using return, although economically intuitive, does not achieve a clear separation of cash flow covariance and duration.

To see this point even more clearly, I work out the decomposition given the mean-reverting cash flow share specification and the Epstein and Zin utility: 


$$
\begin{aligned}
\beta^{i} & =\beta_{C F}^{i}+\beta_{D R}^{i}, \\
\beta_{C F}^{i} & =\phi^{d, i}\left(\kappa_{1}^{i}\right)=\frac{\left(1-\kappa_{1}^{i}\right) \lambda^{i} \phi^{c}(0)}{1-\phi \kappa_{1}^{i}}+\phi^{c}\left(\kappa_{1}^{i}\right), \\
\beta_{D R}^{i} & =\phi^{m}\left(\kappa_{1}^{i}\right)-\phi^{m}(0)=\frac{1}{\psi}\left[\phi^{c}(0)-\phi^{c}\left(\kappa_{1}^{i}\right)\right] .
\end{aligned}
$$

The cash flow covariance measure $\lambda^{i}$ enters the expression of $\beta^{i}$ explicitly whereas cash flow duration measure $z_{t}^{i}$ enters only indirectly through $\kappa_{1}^{i}$. The impact of the duration on consumption beta and expected return is difficult to examine. Assuming $\kappa_{1}^{i}$ constant across stocks effectively eliminates the impact of cash flow duration. This is why I choose to compute the exact solution by examining each equity strip separately.

\section{Appendix 3: Mean-reverting cash flow share in Bansal and Yaron's (2004) economy} - Calibration and simulation

Bansal and Yaron (2004, BY thereafter) study an economy in which: (1) there is a persistent and predictable component in consumption growth, and (2) the economy-wide volatility is time-varying. They show that these dynamics, together with Epstein and Zin's (1989) preferences, can explain key time series properties of asset market. This section of the appendix derives the cross-sectional implication of the mean-reverting cash flow share in BY's economy. The numerical calibration exercise shows that (a) time-varying expected consumption growth and (b) time-varying volatility make relatively small contributions to cross-sectional variation in expected returns. Therefore, the two-factor cash flow model still does a good job in cross-section. This Appendix also serves as a self-contained worked out example that illustrates the model intuition.

A3.1: Bansal and Yaron's (2004) economy

For $\psi \neq 1$, log stochastic discount factor (SDF) for the Epstein and Zin utility can be expressed as:

$$
m_{t+1}=\theta\left[\log \delta-\frac{1}{\psi} \Delta c_{t+1}\right]+(\theta-1) r_{a, t+1} .
$$

Again $\theta=(1-\gamma) /(1-1 / \psi) . \delta$ is the time discount factor; $\gamma$ and $\psi$ represent the coefficients of risk aversion and elasticity of intertemporal substitution, respectively; $\Delta c_{t+1}$ is the log consumption growth and $r_{a, t+1}$ is the log return on the wealth portfolio.

When there is a persistent component in $\Delta c_{t+1}$ and aggregate volatility is time-varying: 


$$
\begin{aligned}
\Delta c_{t+1} & =\mu_{c}+x_{t}+\sigma_{t} w_{t+1} \\
x_{t+1} & =\rho x_{t}+\sigma_{e} \sigma_{t} e_{t+1} \\
\sigma_{t+1}^{2} & =\sigma^{2}+v_{1}\left(\sigma_{t}^{2}-\sigma^{2}\right)+\sigma_{\eta} \eta_{t+1}
\end{aligned}
$$

Appendix A.1 in Bansal and Yaron (2004, A10) then shows: ${ }^{34}$

$$
\begin{aligned}
m_{t+1} & \approx m_{0}+m_{x} x_{t}+m_{\sigma} \sigma_{t}^{2}+m_{w} \sigma_{t} w_{t+1}+m_{e} \sigma_{t} e_{t+1}+m_{\eta} \sigma_{\eta} \eta_{t+1} \\
m_{0} & =\log \delta-\frac{1}{\psi} \mu_{c} \\
m_{x} & =-\frac{1}{\psi} \\
m_{\sigma} & =A_{2}\left(\kappa_{1} v_{1}-1\right)(\theta-1) \\
m_{w} & =-\gamma \\
m_{e} & =(\theta-1) \kappa_{1} A_{1} \sigma_{e} \\
m_{\eta} & =(\theta-1) A_{2} \kappa_{1}, \\
A_{1} & =\frac{1-\frac{1}{\psi}}{1-\kappa_{1} \rho} \\
A_{2} & =\frac{0.5 \theta\left[\left(1-\frac{1}{\psi}\right)^{2}+\left(\kappa_{1} A_{1} \sigma_{e}\right)^{2}\right] \sigma_{t}^{2}}{1-\kappa_{1} v_{1}} \\
\kappa_{1} & =0.997 .
\end{aligned}
$$

The last three terms in $m_{t+1}$ capture risk premium due to innovation in consumption growth, expected growth rate, and time-varying volatility accordingly. Under standard power utility, $\theta=1$, $m_{e}=m_{\eta}=0$ and innovations in expected growth rate and volatility are not priced. When $\psi=1$, $m_{\eta}=0$ and uncertainty in volatility is not priced.

I model the share of cash flow to aggregate consumption as a mean-reverting process. The change in cash flow share is (omitting $i$ superscripts):

$$
\begin{aligned}
\Delta s_{t+1} & =(1-\phi) z_{t}+\lambda \sigma_{t} w_{t+1}+\varepsilon_{t+1}, \\
z_{t+1} & =\phi z_{t}-\lambda \sigma_{t} w_{t+1}-\varepsilon_{t+1} .
\end{aligned}
$$

\footnotetext{
${ }^{34}$ The expression of $m_{t+1}$ is approximate since it is derived using log-linearization on $r_{a, t+1}$.
} 
$\lambda$ measures cash flow covariance risk and $z_{t}=\bar{s}-s_{t}$ measures cash flow duration. The cash flow process in this paper differs from that of BY in two aspects. First, I allow the innovation in cash flow to be contemporaneously correlated with the innovation in consumption growth; therefore. there is a positive equity premium even with standard power utility. Second, I allow the predictable component of cash flow growth $z_{t}$ to vary across stocks, therefore providing an extra degree of freedom to capture the cross-sectional variation in cash flow duration.

A3.2: Solution to expected excess return

Again, I treat a stock as a portfolio of equity strips and solve for the expected return of each equity strip using:

$$
E_{t}\left[M_{t+1} \frac{D_{t+1}}{D_{t}} \frac{P_{n-1, t+1}}{D_{t+1}}\right]=\frac{P_{n, t}}{D_{t}}
$$

I conjecture:

$$
\frac{P_{n, t}}{D_{t}}=\exp \left\{A(n)+B(n) z_{t}+C(n) x_{t}+D(n) \sigma_{t}^{2}\right\} .
$$

Substitute (21), (22), (23) and (25) into (24) and match terms on $z_{t}, x_{t}$ and $\sigma_{t}^{2}$, we have the following system of difference equations:

$$
\begin{aligned}
m_{0}+D(n-1)\left(1-v_{1}\right) \sigma^{2}+\frac{1}{2}\left[m_{\eta}+D(n-1)\right]^{2} \sigma_{\eta}^{2}+A(n-1) & =A(n) \\
\phi B(n-1)+(1-\phi) & =B(n), \\
1+m_{x}+\rho C(n-1) & =C(n), \\
m_{\sigma}+\frac{1}{2}\left[m_{w}+1+\lambda-B(n-1) \lambda\right]^{2}+\frac{1}{2}\left[m_{e}+C(n-1) \sigma_{e}\right]^{2}+D(n-1) v_{1} & =D(n) . \\
\text { subject to initial conditions } A(0), B(0), C(0), D(0) & =0
\end{aligned}
$$

One period innovation in return on individual equity strip is:

$$
\begin{aligned}
& -B(n-1) \lambda \sigma_{t} w_{t+1}+C(n-1) \sigma_{e} \sigma_{t} e_{t+1}+D(n-1) \sigma_{\eta} \eta_{t+1}+\lambda \sigma_{t} w_{t+1}+\sigma_{t} w_{t+1} \\
= & \left(1+\phi^{n-1} \lambda\right) \sigma_{t} w_{t+1}+C(n-1) \sigma_{e} \sigma_{t} e_{t+1}+D(n-1) \sigma_{\eta} \eta_{t+1} .
\end{aligned}
$$

The risk premium is: 


$$
\begin{aligned}
\log E_{t}\left[R_{n, t+1} / R f_{t}\right] & =R P_{1, t}(n)+R P_{2, t}(n)+R P_{3, t}(n) \\
R P_{1, t}(n) & =-m_{w}\left(1+\phi^{n-1} \lambda\right) \sigma_{t}^{2} \\
& =\gamma\left(1+\phi^{n-1} \lambda\right) \sigma_{t}^{2} \\
R P_{2, t}(n) & =-m_{e} C(n-1) \sigma_{e} \sigma_{t}^{2} \\
& =\frac{\left(\gamma-\frac{1}{\psi}\right)\left(1-\frac{1}{\psi}\right) \kappa_{1}\left(1-\rho^{n-1}\right)}{\left(1-\kappa_{1} \rho\right)(1-\rho)} \sigma_{e}^{2} \sigma_{t}^{2} \\
R P_{3, t}(n) & =-m_{\eta} D(n-1) \sigma_{\eta}^{2} .
\end{aligned}
$$

The first term $R P_{1, t}(n)$ captures the usual risk premium in CCAPM. It is increasing in $\lambda$, which means that a higher contemporaneous covariance with consumption growth will lead to a high risk premium. However, since the cash flow share is mean-reverting, the impact of the cash flow covariance decreases with maturity $n$. In particular, if we look at an equity strip with infinite maturity, the corresponding $R P_{1, t}$ is always $\gamma \sigma_{t}^{2}$ and does not depend at all on $\lambda$. For $\lambda>0$, $R P_{1, t}(n)$ is decreasing in $n$; for $\lambda<0, R P_{1, t}(n)$ is increasing in $n$.

The second term $R P_{2, t}(n)$ captures the risk premium arising from the expected growth component $x$. Since $x$ is persistent, the impact of a shock in $x$ on $E_{t} \Delta c_{t+n}$ accumulates. If investors care about long run risk $(\psi>1)$, they will command a positive risk premium, which pushes up risk premium and helps to justify equity premium in $\mathrm{BY}$. This is why for $\psi>1, R P_{1, t}(n)$ is always positive and increasing in $n$ and $\psi$. When $\psi$ is close to $1, R P_{2, t}(n)$ is close to zero. Finally, for a given maturity, $R P_{2, t}(n)$ is a constant across stocks.

The last term $R P_{3, t}(n)$ captures the uncertainty risk. Again, when $\psi>1, R P_{3, t}(n)$ is positive. $R P_{3, t}(n)$, compared to $R P_{1, t}(n)$, varies less in a cross-section. In other words, although time-varying volatility is crucial in explaining the time-series dynamics of asset market, it is less important in explaining cross-sectional variation in averaged returns, at least in BY's economy.

The stock expected return is just a weighted-average of equity strip returns:

$$
E_{t}\left[R_{t+1}^{i} / R f_{t}\right]=\frac{\sum_{n=1}^{\infty} P_{n, t}^{i} \exp \left[R P_{1, t}(n)+R P_{2, t}(n)+R P_{3, t}(n)\right]}{P_{t}^{i}} .
$$

The expected excess return can also be decomposed into three parts as discussed: 


$$
\begin{aligned}
E_{t}\left[R_{t+1}^{i}-R f_{t}\right] & \approx \frac{\sum_{n=1}^{\infty} P_{n, t}^{i}\left[R P_{1, t}(n)+R P_{2, t}(n)+R P_{3, t}(n)\right]}{P_{t}^{i}} \\
& =R P_{1, t}+R P_{2, t}+R P_{3, t}, \\
R P_{k, t} & =\frac{\sum_{n=1}^{\infty} P_{n, t}^{i} R P_{k, t}(n)}{P_{t}^{i}}, k=1,2,3 .
\end{aligned}
$$

The excess return decomposition of (27) allows us to study the relative explanatory power of consumption growth innovation, expected growth rate innovation and time-varying volatility, regarding cross-sectional variation in expected excess returns. We can decompose the cross-sectional variance of excess return as:

$\operatorname{var}_{t}\left[R_{t+1}^{i}-R f_{t}\right]=\operatorname{cov}_{t}\left(R_{t+1}^{i}-R f_{t}, R P_{1, t}\right)+\operatorname{cov}_{t}\left(R_{t+1}^{i}-R f_{t}, R P_{2, t}\right)+\operatorname{cov}_{t}\left(R_{t+1}^{i}-R f_{t}, R P_{3, t}\right)$.

Divide both sides of (28) by $\operatorname{var}_{t}\left[R_{t+1}^{i}-R f_{t}\right]$, we have:

$$
\begin{aligned}
1 & =\beta_{1}+\beta_{2}+\beta_{3}, \\
\beta_{k} & =\operatorname{cov}_{t}\left(R_{t+1}^{i}-R f_{t}, R P_{i, t}\right) / \operatorname{var}_{t}\left[R_{t+1}^{i}-R f_{t}\right], k=1,2,3 .
\end{aligned}
$$

$\beta_{k}$ then measures the percentage contribution of $k$ th term to the cross-sectional variation in expected excess return.

A3.3: Calibration and simulation

The parameters of calibration are obtained from Bansal and Yaron (2004). Specifically, they are: $\delta=0.998, \gamma=10, \mu_{c}=0.0015, \rho=0.979, \sigma_{e}=0.044, v_{1}=0.987$ and $\sigma_{\eta}=2.3 \times 10^{-6}$. The only exception is that I use a higher $\sigma(.011)$ than BY (0.0078), since the annual consumption growth computed using quarterly time-aggregated consumption data tends to underestimate the true volatility of "spot" consumption growth. ${ }^{35}$ All numbers correspond to a monthly decision horizon. For the baseline case, I also set $\psi=1.5, \phi=0.99, \sigma_{t}^{2}=\sigma^{2}$ and $x_{t}=0$. I vary $\lambda$ from -1.5 to 7.5 and and $z$ from -2.5 to 2.5 with increments of 0.1 to generate a cross-section of expected excess returns numerically using the true asset pricing model (26).

\footnotetext{
${ }^{35}$ Please refer to Breeden, Gibbons and Litzenberger (1989) for an excellent discussion of this "summation" bias in consumption data. They also show the standard deviation of annual consumption (absolute) change measured using quarterly data is $2 / 3$ of the true value.
} 
I first numerically compute a fixed-income Macaulay duration measure in the baseline case as a present value weighted time (in year):

$$
\frac{\sum_{n=1}^{\infty} P_{n} \cdot n}{P} .
$$

Figure 1 plots such Macaulay duration as a function of cash flow duration $z$ and cash flow covariance $\lambda$. It is clear that for the same value of $\lambda$, cash flow duration and Macaulay duration are always monotonically related to each other.

Figure 2 plots the expected excess return and cashflow-to-price ratio as functions of cash flow duration and covariance for the baseline case. Consistent with the intuition behind my model, the impact of duration $z$ depends on the sign of $\lambda$ even though expected excess return is always increasing in cash flow covariance $\lambda$. For $\lambda>0$, the expected return decreases in $z$; for $\lambda<0$, the expected return increases in $z$. The cash flow to price ratio is clearly decreasing in the cash flow duration measure $z$, and for the range of $\lambda$ considered in the simulation, the cash flow to price ratio is increasing in $\lambda$. In addition, I am able to fit equity premium of $6.6 \%$ and market cash flow to price ratio of 18.3 using a $\lambda$ around 5.5, which is consistent with Longstaff and Piazzesi (2004), in which the calibrated loading of the corporate fraction on consumption growth is around 6 .

I then consider cross-sectional regressions of the two-factor model with cash flow duration:

$$
E_{t}\left[R_{t+1}^{i}-R f_{t}\right]=\gamma_{0}+\gamma_{1} \lambda^{i}+\gamma_{2}\left(z_{t}^{i} \lambda^{i}\right)
$$

a one-factor model without cash flow duration:

$$
E_{t}\left[R_{t+1}^{i}-R f_{t}\right]=\gamma_{0}+\gamma_{1} \lambda^{i}
$$

and a three-factor model:

$$
E_{t}\left[R_{t+1}^{i}-R f_{t}\right]=\gamma_{0}+\gamma_{1} \lambda^{i}+\gamma_{2}\left(z_{t}^{i} \lambda^{i}\right)+\gamma_{3} z_{t}^{i} .
$$

The regression R-squares are reported for various cases in Table 1. In addition, for each case, I decompose the cross-sectional variation in excess returns into three parts: the variation due to consumption growth innovation, expected growth rate innovation and time-varying volatility respectively. The relative importance of the three components, as measured by $\beta_{1}, \beta_{2}$ and $\beta_{3}$, are also reported in Table 1.

The variance decomposition shows the expected growth rate innovation and time-varying volatility to be less important in determining the cross-sectional variation in expected excess 
returns. In most of the cases I consider, the variation is primarily driven by contemporaneous consumption innovations. Consequently, the two-factor model should capture most of the variation. This is confirmed by the fact that the cross-sectional regression R-squares of the two-factor model are usually above $95 \%$. Adding the third factor provides very little incremental R-squares. However, if we ignore cash flow duration and only consider cash flow covariance, the R-square will decrease by $25 \%$ on average.

The two factor cash flow model approximation is illustrated graphically in Figure 3 for the baseline case. The true return surface is plotted on the left and can be nicely approximated by the return surface of the two factor cash flow model on the right. Table 1 also investigates the impact of cross-sectional variation in the parameter of mean-reverting speed $\phi$, which I assume to be constant. In addition to varying $\lambda$ and $z$, I also vary $\phi$ from 0.96 to 0.995 and generate a new cross-section. The two-factor cash flow model still does a reasonably good job of explaining approximately $80 \%$ of the cross-sectional return variations, even with the existence of a sizable dispersion in the mean-reverting speed. In contrast, if we ignore cash flow duration, the R-square will decrease by almost $30 \%$.

\section{Appendix 4: Econometric Issues}

A4.1: Robust standard error estimation for the two-factor cash flow model

I want to estimate the two-factor cash flow model (equation 1) empirically as:

$$
E\left[R_{t+1}^{i}-R f_{t}\right]=\gamma_{0}+\gamma_{1} \operatorname{Cov}+\gamma_{2} \operatorname{Cov} \times \text { Dur } .
$$

The risk premium $\left[\gamma_{0}, \gamma_{1}, \gamma_{2}\right]$ is consistently estimated using an OLS cross-sectional regression on the 20 portfolios. However, the OLS standard errors are biased downward since they do not account for the estimation errors in Cov and Dur. Following Cochrane (2001) and Bansal, Dittmar and Lundblad (2002), I compute the robust standard errors by stacking moment conditions in both time-series regressions and cross-sectional regressions in a one-stage GMM system.

Recall from equation (10) that Cov is identified in a time-series regression of:

$$
\sum \tilde{e}_{t}^{i}=\lambda_{0}^{i}+\operatorname{Cov}^{i} \sum w_{t}
$$

where 


$$
\begin{aligned}
\sum \widetilde{e}_{t}^{i} & =\sum_{n=0}^{\infty} \rho^{n}\left[e^{i}(t, n+1)-\Delta c_{t+n+1}\right] \\
\sum w_{t} & =\sum_{n=0}^{\infty} \rho^{n} \phi^{c}(0) w_{t+n+1} .
\end{aligned}
$$

This corresponds to 40 moment conditions that identify $\left[\lambda_{0}, C o v\right]$ :

$$
\begin{aligned}
E\left[\sum \widetilde{e}_{t}^{i}-\lambda_{0}^{i}-\operatorname{Cov}^{i} \sum w_{t}\right] & =0 \forall i=1, \ldots, 20, \\
E\left[\operatorname{Cov}^{i}\left(\sum \widetilde{e}_{t}^{i}-\lambda_{0}^{i}-\operatorname{Cov}^{i} \sum w_{t}\right)\right] & =0 \forall i=1, \ldots, 20 .
\end{aligned}
$$

Likewise, recall from equation (9) that Dur can be identified from moment conditions:

$$
E\left[\sum z_{t}^{i}-D u r^{i}\right]=0 \forall i=1, \ldots, 20,
$$

where

$$
\sum z_{t}^{i}=\Sigma_{t}^{e i}-\frac{\kappa+\mu_{c}}{1-\rho}-\gamma_{t}^{i}
$$

Finally, $\left[\gamma_{0}, \gamma_{1}, \gamma_{2}\right]$ can be identified by exploiting the following set of moment conditions:

$$
\left.E R_{t+1}^{i}-R f_{t}-\gamma_{0}-\gamma_{1} \operatorname{Cov}^{i}-\gamma_{2} \operatorname{Cov}^{i} \times D u r^{i}\right]=0 \forall i=1, \ldots, 20 .
$$

All the parameters in the system can now be summarized in a $63 \times 1$ vector:

$$
\Psi=\left[\begin{array}{llll}
\lambda_{0}^{\prime} & \operatorname{Cov}^{\prime} \operatorname{Dur}^{\prime} \gamma_{0} & \gamma_{1} & \gamma_{2}
\end{array}\right]^{\prime}
$$

I stack the sample counterparts to the moment conditions (29) to (32) in the following manner:

$$
g_{T}(\Psi)=\frac{1}{T} \sum f\left(X_{t}, \Psi\right),
$$

and $g_{T}(\Psi)$ is a $80 \times 1$ vector. I then construct an exactly identified system:

$$
A_{T}^{\prime} g_{T}=0
$$

$A_{T}$ is a $80 \times 63$ matrix chosen in a such a way that the estimates of $\left[\gamma_{0}, \gamma_{1}, \gamma_{2}\right]$ coincide with the cross-sectional OLS estimates. Specifically, we have:

$$
A_{T}=\left[\begin{array}{cccc}
I_{60 \times 60} & 0_{60 \times 1} & 0_{60 \times 1} & 0_{60 \times 1} \\
0_{20 \times 60} & 1_{20 \times 1} & \text { Cov } & \text { Cov } \times \text { Dur }
\end{array}\right],
$$


where $I$ denotes the identity matrix, 0 denotes vector or matrix of zeros and 1 denotes vector or matrix of ones. We know that:

$$
\sqrt{T}\left(\Psi_{T}-\Psi_{0}\right) \sim N\left(0,(A D)^{-1}\left(A S A^{\prime}\right)(A D)^{-1^{\prime}}\right)
$$

where $S$ is the variance-covariance matrix of the moment conditions, for which the sample counterpart is estimated using Newey and West formula with 7 leads and lags, and $D$ is the gradient of $g_{T}$. In this case, $g_{T}$ is computed as:

$$
\begin{aligned}
& D_{63 \times 80}=\left[\begin{array}{lll}
D_{1} & D_{2} & D_{3}
\end{array}\right], \\
& D_{1}=\left[\begin{array}{cc}
I_{20 \times 20} & E\left[\sum w_{t}\right] \times I_{20 \times 20} \\
E\left[\sum w_{t}\right] \times I_{20 \times 20} & E\left[\left(\sum w_{t}\right)^{2}\right] \times I_{20 \times 20} \\
0_{23 \times 20} & 0_{23 \times 20}
\end{array}\right], \\
& D_{2}=\left[\begin{array}{c}
0_{40 \times 20} \\
I_{20 \times 20} \\
0_{3 \times 20}
\end{array}\right] \text {, } \\
& D_{3}=\left[\begin{array}{c}
0_{20 \times 20} \\
\operatorname{diag}\left(\gamma_{1}+\gamma_{2} \text { Dur }\right) \\
\operatorname{diag}\left(\gamma_{2} \text { Cov }\right) \\
1_{1 \times 20} \\
\text { Cov }^{\prime} \\
\operatorname{Cov} \times \text { Dur' }
\end{array}\right] \text {, }
\end{aligned}
$$

where $\operatorname{diag}(X)$ denotes a diagonal matrix whose diagonal elements are elements of the vector $X$. The robust standard errors computed in (33) not only account for estimation errors in Cov and Dur during the time-series regressions, but also adjust for possible error correlations across section and across time.

A4.2: Robust standard error estimation for the Panel regression

I wish to estimate the following relation in a panel data setting with cross-sectional size of $N$ (balanced panel with $N$ clusters) and time-series length of $T$ :

$$
Y_{i t}=\alpha+X_{i t-1} \beta+u_{i t}
$$

where I assume $X$ is uncorrelated with $u$ so $\beta$ can be estimated consistently with OLS. In the context of the paper, $Y_{i t}$ is the discounted sum of all future $\log$ ROEs from $t$ for portfolio $i$ and 
$X_{i t-1}$ is a vector of instruments measurable at time $t-1$ of portfolio $i$. Since $Y_{i t}$ is measured across over-lapping periods, I would expect $u_{i t}$ to be correlated across time. In addition, I allow $u_{i t}$ to be correlated across portfolio since I expect earnings to increase (decrease) for most firms during boom (recession). Specifically, I assume:

$$
u_{i t}=v_{t}+\varepsilon_{i t}
$$

where $v_{t}$ is a fixed "time" effect capturing cross-sectional correlation of the error terms. $\varepsilon_{i t}$ is independent across $i$ but could be correlated across time. I do not impose a specific structure on $\varepsilon_{i t}$. It could contain both fixed "portfolio" effect and a time decaying term.

It is straightforward to eliminate the fixed "time" effect through a cross-sectional demean procedure:

$$
Y_{i t}-\overline{Y_{t}}=\left(X_{i t-1}-\overline{X_{t-1}}\right) \beta+\varepsilon_{i t}-\overline{\varepsilon_{t}}
$$

where variables with an upper bar denote those variables' cross-sectional mean at time $t$.

Define

$$
\begin{aligned}
Y_{i t}^{*} & =Y_{i t}-\overline{Y_{t}}, \\
X_{i t-1}^{*} & =X_{i t-1}-\overline{X_{t-1}}, \\
\varepsilon_{i t}^{*} & =\varepsilon_{i t}-\overline{\varepsilon_{t}}
\end{aligned}
$$

(34) becomes:

$$
Y_{i t}^{*}=X_{i t-1}^{*} \beta+\varepsilon_{i t}^{*}
$$

Without imposing distributional assumption, I can estimate $\beta$ and its standard error using GMM with moment conditions:

$$
f=E\left[X^{*}\left(Y^{*}-X^{*} \beta\right)\right]=0 .
$$

The estimate of $\beta$ is numerically identical to the OLS estimate $\left(X^{* \prime} X^{*}\right)^{-1} X^{*} Y^{*}$ and

$$
\operatorname{var}(\beta)=d^{-1} S d^{-1 \prime}
$$

where 


$$
d=X^{* \prime} X^{*}
$$

and $S$ is computed using Newey-West method with $M$ lags:

$$
\begin{aligned}
S & =\sum_{i=1}^{N}\left(\sum_{t=1}^{T} X_{i t-1}^{* \prime} \varepsilon_{i t}^{* \prime} \varepsilon_{i t}^{*} X_{i t-1}^{*}+2 \sum_{t=1}^{T-1} \sum_{s=t+1}^{T} w(t-s) X_{i t-1}^{* \prime} \varepsilon_{i t}^{* \prime} \varepsilon_{i t s}^{*} X_{i s-1}^{*}\right) \\
w(t-s) & =1-(t-s) /(M+1) .
\end{aligned}
$$




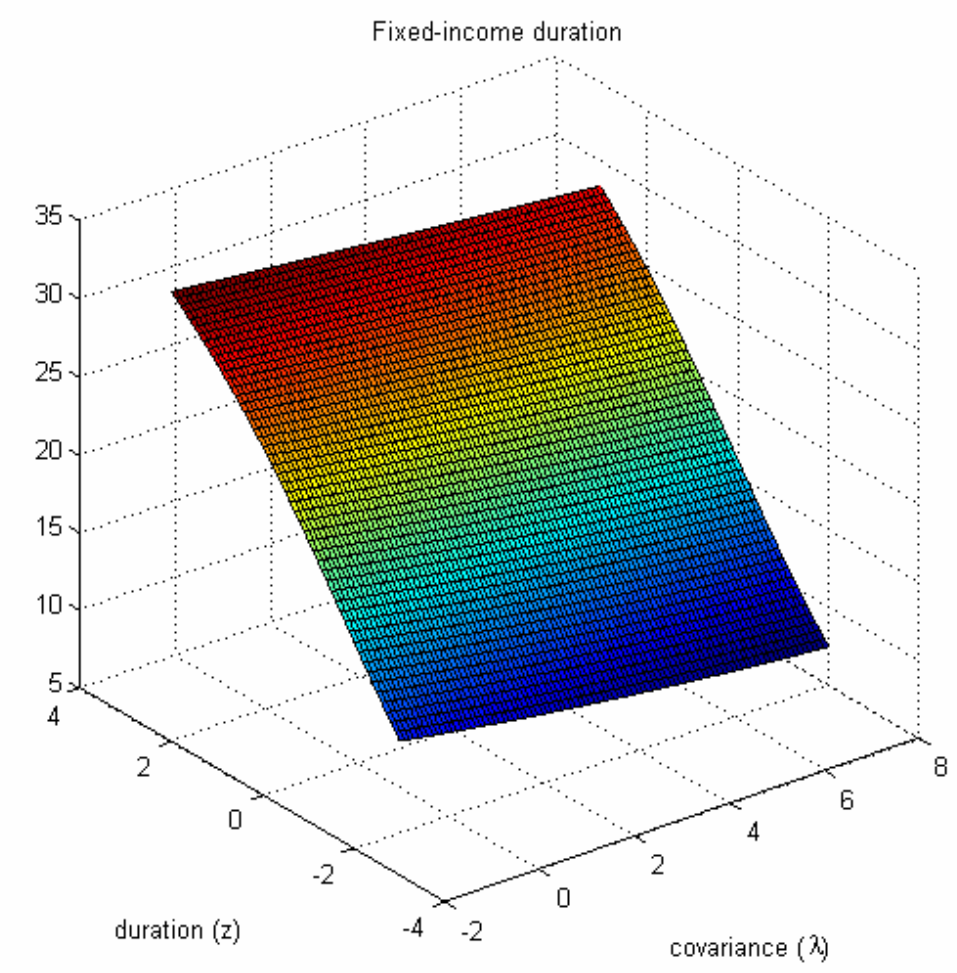

Figure 1: Relationship between the cash flow duration $(\mathrm{z})$ and the fixed-income Macaulay duration for various cash flow covariances in Bansal and Yaron's (2004) economy. The parameters for the baseline case are found in Appendix A3.3. 

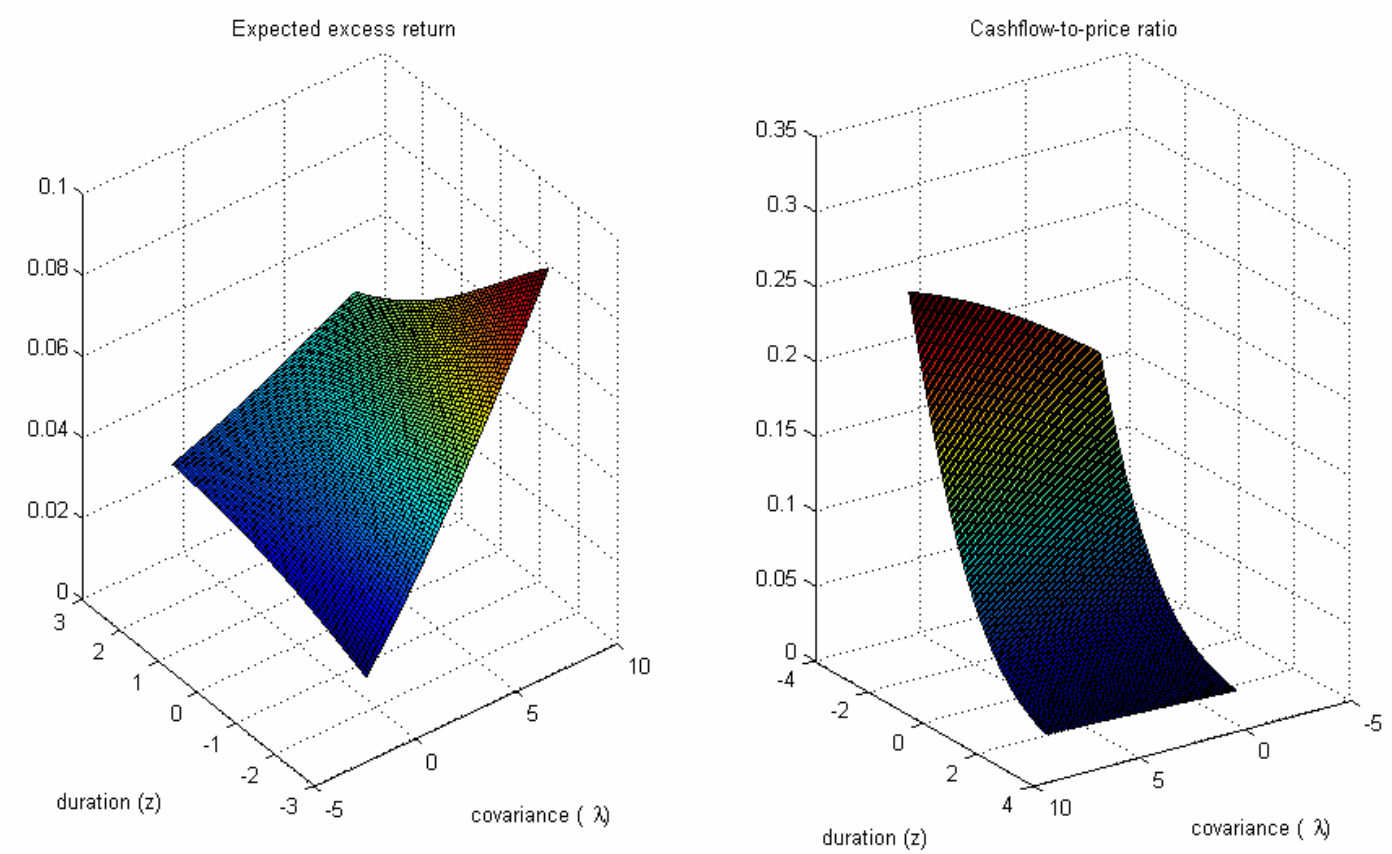

Figure 2: Expected return and cash-flow-to-price ratio as functions of duration and covariance risk for the baseline case in Bansal and Yaron's (2004) economy. The parameters for the baseline case are found in Appendix A3.3. 


$$
E_{t}\left[R_{t+1}^{i} / R f_{t}\right]=\frac{\sum_{n=1}^{\infty} P_{n, t}^{i} E_{t}\left[R_{n, t+1}^{i} / R f_{t}\right]}{P_{t}^{i}} \Rightarrow E_{t}\left[R_{t+1}^{i}-R f_{t}\right]=\gamma_{0}+\gamma_{1} \lambda^{i}+\gamma_{2} \lambda^{i} \cdot z_{t}^{i}
$$
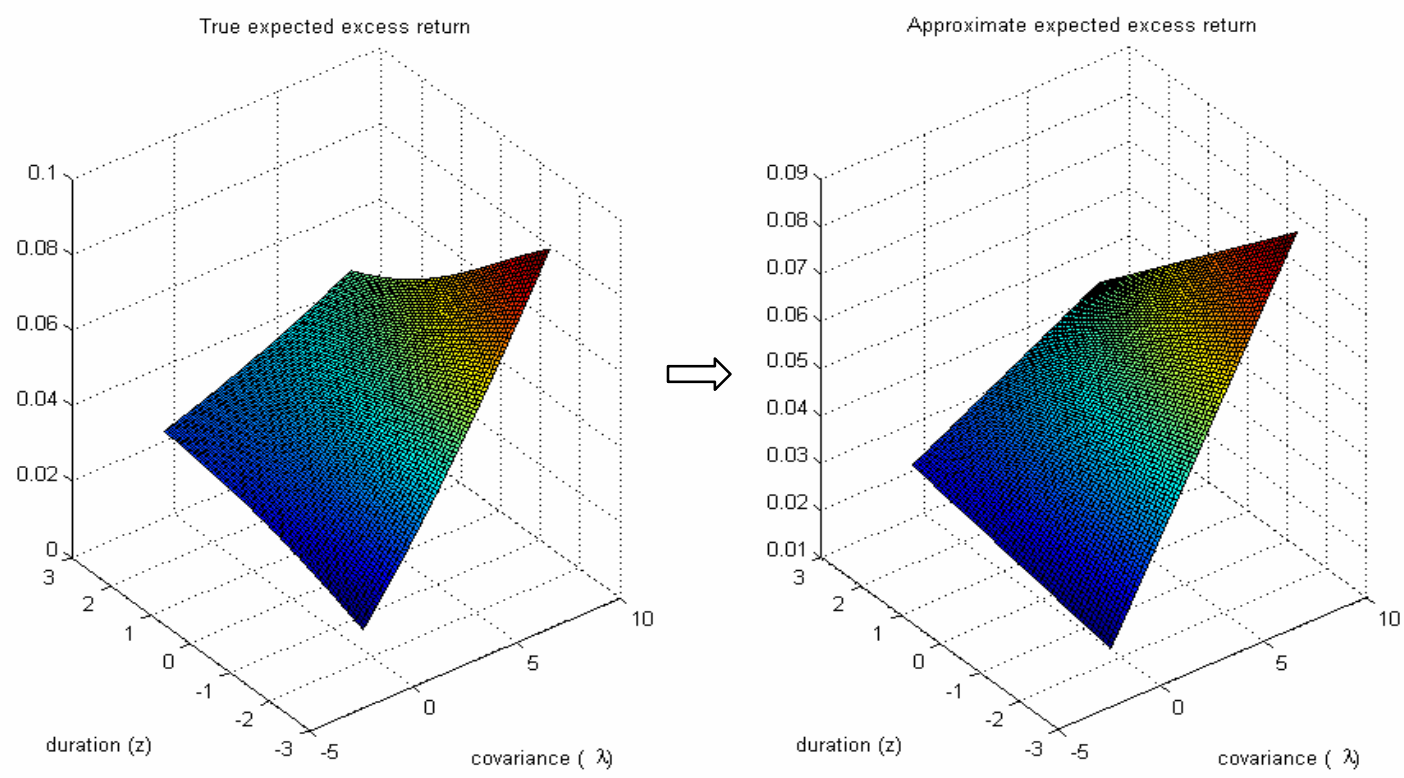

Figure 3: Two-factor cash flow model as an approximation for the baseline case in Bansal and Yaron's (2004) economy. The parameters for the baseline case are found in Appendix A3.3. 
Holding period dimension

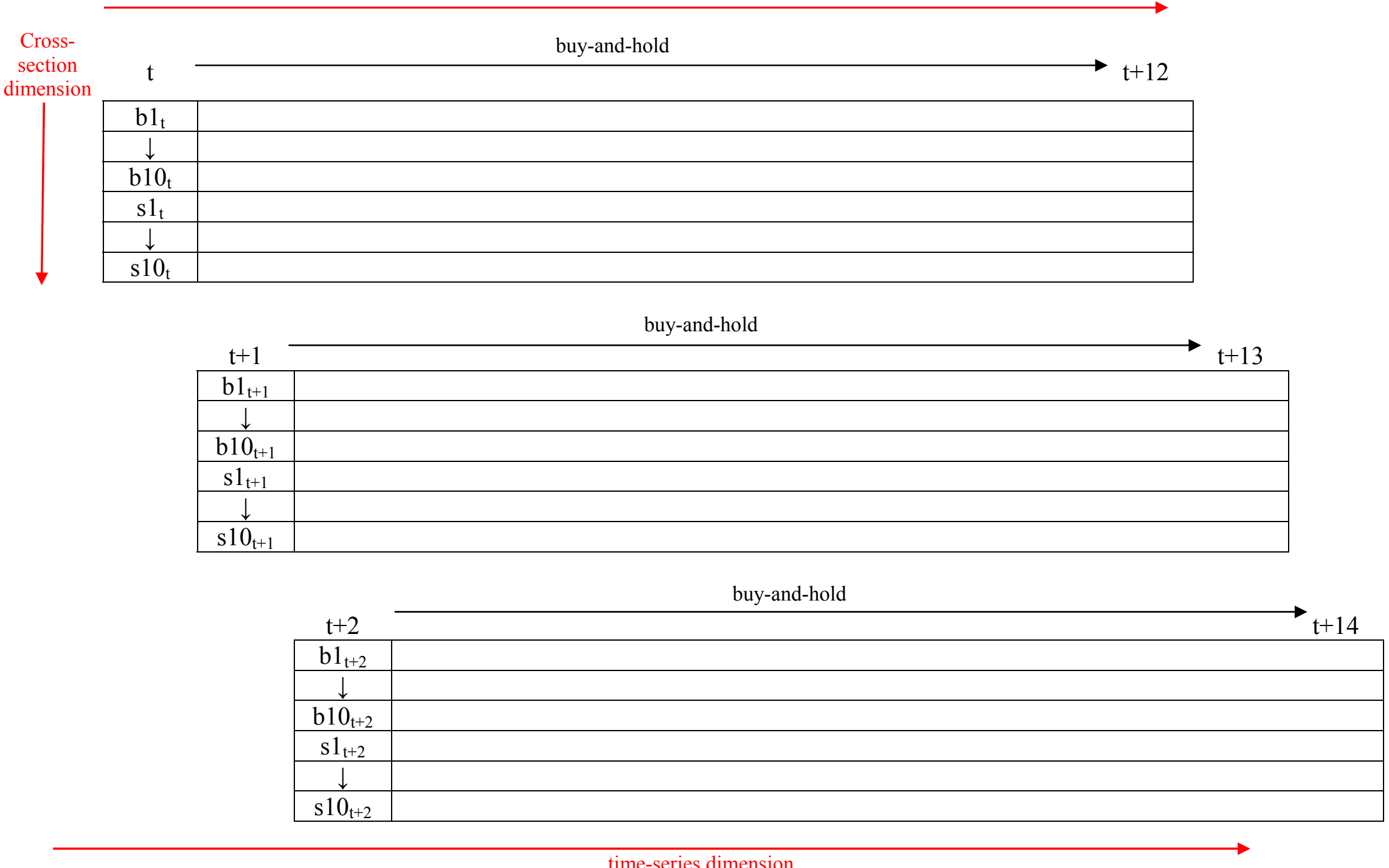

Figure 4: Each year, 10 size-sorted and 10 book-to-market-sorted portfolios are formed and held for 12 years. 

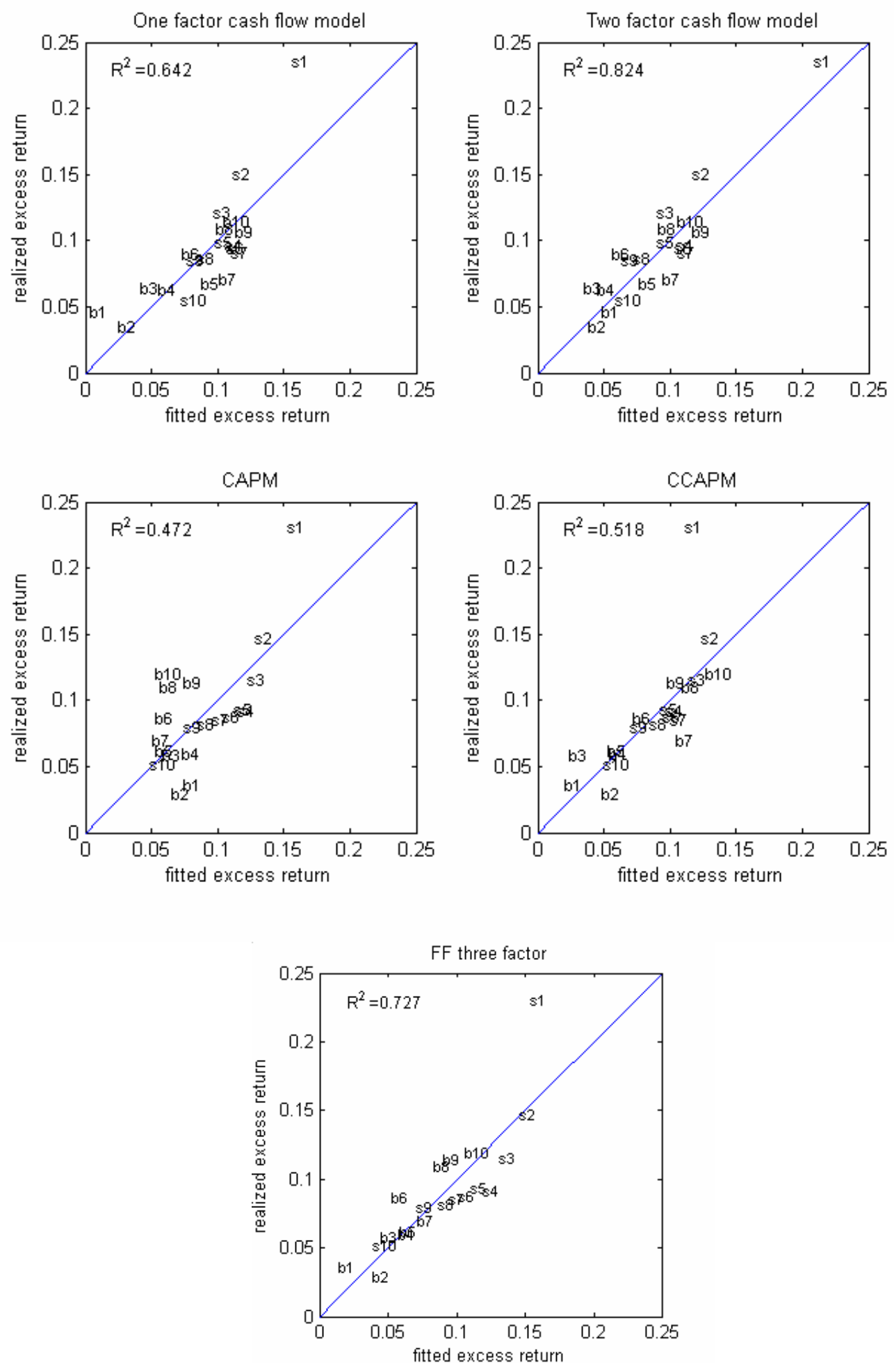

Figure 5: Realize and fitted excess returns of 20 portfolios. b1 and b10 are the extreme growth and value portfolios respectively and s1 and s10 are the smallest and biggest portfolios respectively. Details of the cross-sectional regressions are in Table 5. 

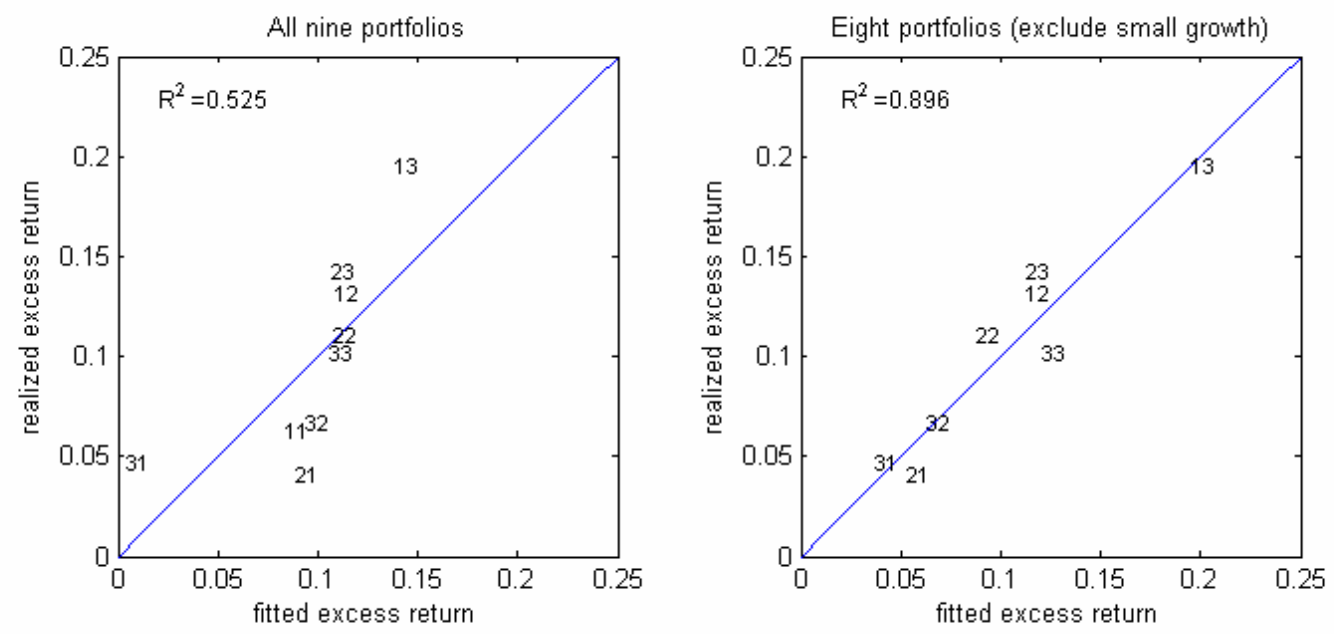

Figure 6: Realize and fitted excess returns of book-to-market (BM) and size double sorted portfolios. The first digit of the portfolio ID represents size rank (1: small and 3: big) and the second digit represents BM rank (1: low book-to-market and 5: high book-to-market). Details of the cross-sectional regressions are in Table 7. 


\section{Table 1: Cross-sectional regression and variance decomposition using simulated data}

I vary $\lambda$ from -1.5 to 7.5 and $\mathrm{z}$ from -2.5 to 2.5 with increments of 0.1 , to generate a cross-section of expected excess returns numerically using the true asset pricing model. I then consider crosssectional regressions of the two-factor model with cash flow duration:

Two-factor model: $E_{t}\left[R_{t+1}^{i} / R f_{t}\right]=\gamma_{0}+\gamma_{1} \lambda^{i}+\gamma_{2}\left(z_{t}^{i} \lambda^{i}\right)$,

, a one-factor model without cash flow duration:

One-factor model: $E_{t}\left[R_{t+1}^{i} / R f_{t}\right]=\gamma_{0}+\gamma_{1} \lambda^{i}$,

and a three-factor model:

Three-factor model: $E_{t}\left[R_{t+1}^{i} / R f_{t}\right]=\gamma_{0}+\gamma_{1} \lambda^{i}+\gamma_{2}\left(z_{t}^{i} \lambda^{i}\right)+\gamma_{3} z_{t}^{i}$.

The regression R-squares are reported for various cases. In addition, for each case, I decompose the cross-sectional variation in excess returns into three parts: the variation due to consumption growth innovation, expected growth rate innovation and time-varying volatility respectively. The relative importance of the three components, as measured by $\beta_{1}, \beta_{2}$ and $\beta_{3}$, are also reported.

Finally, in addition to varying $\lambda$ and z, I also vary cash flow share mean reverting speed: $\phi$ from 0.96 to 0.995 and report the R-squares of the regressions with this larger cross-section.

The parameters for the baseline case are found in Appendix A3.3.

\begin{tabular}{|c|c|c|c|c|c|c|}
\hline & \multicolumn{3}{|c|}{ Regression R-square } & \multicolumn{3}{|c|}{ Variance Decomposition } \\
\hline & One-factor & Two-factor & Three-factor & $\beta_{1}$ & $\beta_{2}$ & $\beta_{3}$ \\
\hline \multicolumn{7}{|l|}{ Baseline } \\
\hline & $80.5 \%$ & $98.8 \%$ & $99.4 \%$ & 1.043 & -0.055 & 0.013 \\
\hline \multicolumn{7}{|c|}{ Risk aversion: $\gamma$} \\
\hline 5 & $78.1 \%$ & $98.9 \%$ & $99.5 \%$ & 1.042 & -0.044 & 0.002 \\
\hline 15 & $78.2 \%$ & $98.0 \%$ & $98.6 \%$ & 1.042 & -0.074 & 0.032 \\
\hline \multicolumn{7}{|c|}{ Cash flow share mean reverting speed: $\phi$} \\
\hline 0.96 & $64.0 \%$ & $93.6 \%$ & $96.2 \%$ & 1.043 & -0.055 & 0.013 \\
\hline \multicolumn{7}{|l|}{ IES: $\psi$} \\
\hline 0.5 & $48.7 \%$ & $95.3 \%$ & $97.7 \%$ & 0.772 & 0.211 & 0.017 \\
\hline \multicolumn{7}{|c|}{ Consumption growth volatility: $\sigma$} \\
\hline 0.008 & $79.0 \%$ & $98.7 \%$ & $99.5 \%$ & 1.023 & -0.049 & 0.026 \\
\hline 0.014 & $83.0 \%$ & $98.6 \%$ & $99.2 \%$ & 1.054 & -0.061 & 0.007 \\
\hline
\end{tabular}

Cash flow share mean reverting speed: $\phi$ varying from 0.96 to 0.995

$50.7 \% \quad 79.5 \% \quad 81.2 \%$ 


\section{Table 2: Descriptive statistics of 20 portfolios}

At June each year, I sort all stocks of industrial firms traded on NYSE, AMEX and NASDAQ into 10 size-sorted portfolios and 10 book-to-market-sorted portfolios. The portfolio characteristics at formation, annual returns and annual excess returns (in excess of risk free rate) first year after portfolio formation, are reported. All values are time-series averages across a sampling period from 1964 to 2002. Market Equity (ME) is measured in millions. BM denotes the book-to-market ratio and $\mathrm{D} / \mathrm{P}$ denotes the dividend yield where the dividend also includes share repurchase.

I also directly test the validity of the $\mathrm{AR}(1)$ assumption on the cash flow share for the 20 portfolios. I first fit an AR(1) process for the cash flow share and compute the residuals. I then test whether these residuals violate the white noise condition using the Ljung-Box Q test. Both the Ljung-Box (LB) Q test statistics and the associated p-values are reported. In addition, I also test the stationarity of the cash flow share using the Augmented Dickey - Fuller test with a constant and a lag of one. The $t$-values are reported $(* *$ means the hypothesis of a unit root can be rejected at $99 \%$ confidence level and * means the hypothesis can be rejected at $95 \%$ confidence level). The cash flow share in year $t$ is computed as the log of the ratio between the portfolio cash flow (sum of common dividend and common share repurchase) and aggregate consumption during year $t$.

Panel A: 10 book-to-market (BM) sorted portfolios

\begin{tabular}{lcccccccccc}
\hline & growth & 2 & 3 & 4 & 5 & 6 & 7 & 8 & 9 & value \\
\cline { 2 - 10 } ME & 1955.2 & 1334.0 & 992.4 & 889.4 & 640.1 & 561.5 & 458.0 & 356.1 & 269.6 & 143.8 \\
BM & 0.155 & 0.290 & 0.407 & 0.522 & 0.641 & 0.770 & 0.920 & 1.106 & 1.369 & 1.858 \\
D/P & 0.018 & 0.026 & 0.032 & 0.035 & 0.039 & 0.044 & 0.046 & 0.047 & 0.052 & 0.050 \\
Return & 0.108 & 0.100 & 0.126 & 0.124 & 0.123 & 0.144 & 0.136 & 0.161 & 0.163 & 0.174 \\
Excess return & 0.045 & 0.037 & 0.063 & 0.061 & 0.060 & 0.081 & 0.073 & 0.098 & 0.100 & 0.111 \\
LB Q test stat & 7.48 & 5.91 & 15.90 & 15.70 & 10.62 & 12.38 & 6.45 & 27.52 & 9.96 & 10.57 \\
p-value & 0.680 & 0.822 & 0.103 & 0.108 & 0.388 & 0.261 & 0.776 & 0.002 & 0.444 & 0.392 \\
ADF t-value & $-5.32^{\star *}$ & $-4.24^{\star *}$ & $-3.65^{\star *}$ & $-11.19^{\star \star}$ & $-5.91^{\star \star}$ & $-6.78^{\star *}$ & $-3.36^{*}$ & $-3.33^{\star}$ & -1.37 & $-3.01^{*}$ \\
\hline
\end{tabular}

Panel B: 10 size (ME) sorted portfolios

\begin{tabular}{lccccccccccc}
\hline & small & 2 & 3 & 4 & 5 & 6 & 7 & 8 & 9 & big \\
\cline { 2 - 10 } ME & 4.3 & 10.4 & 19.0 & 31.6 & 52.1 & 87.6 & 151.7 & 282.9 & 651.6 & 6184.6 \\
BM & 1.100 & 0.977 & 0.932 & 0.871 & 0.819 & 0.770 & 0.733 & 0.678 & 0.632 & 0.575 \\
D/P & 0.021 & 0.023 & 0.024 & 0.024 & 0.024 & 0.026 & 0.027 & 0.028 & 0.030 & 0.037 \\
Return & 0.272 & 0.190 & 0.173 & 0.148 & 0.151 & 0.148 & 0.138 & 0.136 & 0.138 & 0.116 \\
Excess return & 0.209 & 0.127 & 0.111 & 0.085 & 0.088 & 0.085 & 0.075 & 0.073 & 0.075 & 0.053 \\
LB Q test stat & 5.37 & 7.16 & 13.80 & 9.21 & 10.34 & 4.05 & 3.71 & 10.51 & 10.05 & 5.28 \\
p-value & 0.865 & 0.711 & 0.182 & 0.512 & 0.411 & 0.945 & 0.959 & 0.397 & 0.436 & 0.872 \\
ADF t-value & $-8.11^{\star \star}$ & $-6.10^{\star \star}$ & $-5.22^{\star *}$ & $-7.79^{\star \star}$ & $-7.01^{\star \star}$ & $-7.62^{\star \star}$ & -1.16 & -1.64 & $-3.03^{\star}$ & $-4.71^{\star \star}$ \\
\hline
\end{tabular}




\section{Table 3: Cash flow duration measures of 20 portfolios}

I measure duration risk using:

$$
\operatorname{Dur}=E\left[\sum_{t}^{e}\right]-E\left[\gamma_{t}\right]-\frac{\kappa-\mu_{c}}{1-\rho},
$$

where $E\left[\sum_{t}^{e}\right]$ is the average sum of discounted future accounting returns since portfolio formation. Its estimation is discussed in Section IV, A.2 of the paper. The cutoff $N$ is chosen to be 5; $E\left[\gamma_{t}\right]$ is the average $\log$ cash-flow-to-book-equity ratio at portfolio formation and $\frac{\kappa-\mu_{c}}{1-\rho}=$ 4.43 in the sampling period from 1964-1997. The t-values are computed using GMM standard errors which account for both cross-sectional and time-series error correlations with Newey-West formula of 5 leads and lags. The last two columns report the differences in the cash flow duration estimates between extreme portfolios.

Panel A: 10 book-to-market (BM) sorted portfolios

\begin{tabular}{ccccccccccccc} 
& & & & & & & & & & & & $(1,2,3)-$ \\
$\left.E\left[\sum_{t}\right]_{t}\right]$ & 3.40 & 3.04 & 2.66 & 2.46 & 2.15 & 2.00 & 1.74 & 1.56 & 1.23 & 0.87 & & \\
$E\left[\gamma_{t}\right]$ & -2.35 & -2.44 & -2.54 & -2.66 & -2.71 & -2.79 & -2.89 & -3.04 & -3.16 & -3.52 & & \\
Dur & 1.32 & 1.05 & 0.77 & 0.69 & 0.43 & 0.36 & 0.20 & 0.17 & -0.04 & -0.04 & 1.36 & 1.02 \\
t-value & 9.56 & 13.14 & 10.32 & 8.45 & 3.12 & 2.60 & 1.29 & 1.28 & -0.18 & -0.28 & 6.16 & 5.61 \\
\hline
\end{tabular}

Panel B: 10 size (ME) sorted portfolios

\begin{tabular}{|c|c|c|c|c|c|c|c|c|c|c|c|c|}
\hline & small & 2 & 3 & 4 & 5 & 6 & 7 & 8 & 9 & big & $(1-10)$ & $\begin{array}{l}(1,2,3)- \\
(8,9,10)\end{array}$ \\
\hline$E\left[\sum_{t}^{e}\right]$ & 0.03 & 0.46 & 0.73 & 0.81 & 1.05 & 1.30 & 1.49 & 1.76 & 1.89 & 2.35 & & \\
\hline & -4.07 & -3.80 & -3.73 & -3.57 & -3.46 & -3.35 & -3.27 & -3.14 & -3.01 & -2.62 & & \\
\hline Dur & -0.33 & -0.17 & 0.03 & -0.05 & 0.08 & 0.21 & 0.33 & 0.47 & 0.46 & 0.54 & -0.87 & -0.65 \\
\hline $\mathrm{t}$-value & -1.02 & -0.59 & 0.14 & -0.18 & 0.31 & 0.91 & 1.73 & 2.85 & 3.23 & 4.39 & -3.32 & -3.59 \\
\hline
\end{tabular}




\section{Table 4: Cash flow covariance measures of 20 portfolios}

I regress $\sum_{n=0}^{N} \rho^{n}\left[e(t, n+1)-\Delta c_{t+n+1}\right]$ on $\sum_{n=0}^{N} \rho^{n} \phi^{c}(0) w_{t+n+1}$ for each of the 20 portfolios, where $\left\{\phi^{c}(0) w_{t}\right\}$ are consumption growth innovations. The regression coefficient $C o v$ measures the cash flow covariance up to a scaling factor. I repeat the regressions for different horizon $-\mathrm{N}$, and the associated sampling period for each $\mathrm{N}$ is from 1964 to $2002-\mathrm{N}$. I report the OLS estimates in the first row and the associated t-values below. The t-values are computed using GMM standard errors which account for both cross-sectional and time-series error correlations with Newey-West formula of $\mathrm{N}$ leads and lags. The last two columns report the differences in the cash flow covariance estimates between extreme portfolios.

The estimates of $\mathrm{Cov}$ at the horizon of $\mathrm{N}=7$ are finally chosen as the measures of covariance risk. They are highlighted in bold.

Panel A: 10 book-to-market (BM) sorted portfolios

\begin{tabular}{|c|c|c|c|c|c|c|c|c|c|c|c|c|}
\hline & growth & 2 & 3 & 4 & 5 & 6 & 7 & 8 & 9 & value & $(1-10)$ & $\begin{array}{l}(1,2,3)- \\
(8,9,10)\end{array}$ \\
\hline \multirow[t]{2}{*}{$\mathrm{N}=5$} & -3.78 & -2.54 & -2.00 & -1.38 & -0.50 & -0.61 & 0.13 & 0.00 & 1.25 & 0.98 & -4.76 & -3.52 \\
\hline & -2.38 & -3.61 & -3.17 & -1.86 & -0.54 & -0.66 & 0.13 & 0.00 & 0.92 & 1.41 & -2.24 & -2.24 \\
\hline \multirow[t]{2}{*}{$N=7$} & -4.39 & -3.33 & -2.50 & -1.81 & -0.20 & -0.96 & 0.43 & 0.32 & 1.04 & 0.79 & -5.18 & -4.12 \\
\hline & -2.58 & -3.35 & -3.91 & -1.80 & -0.17 & -0.95 & 0.44 & 0.35 & 0.90 & 1.35 & -2.37 & -2.47 \\
\hline \multirow[t]{2}{*}{$\mathrm{N}=10$} & -4.39 & -4.15 & -2.89 & -2.95 & -0.74 & -1.48 & -0.50 & -0.22 & 0.29 & 0.03 & -4.42 & -3.84 \\
\hline & -1.54 & -2.27 & -3.08 & -5.09 & -0.91 & -1.96 & -1.32 & -0.33 & 0.57 & 0.13 & -1.48 & -1.76 \\
\hline \multirow[t]{2}{*}{$\mathrm{N}=12$} & -3.58 & -3.75 & -3.50 & -3.71 & -1.67 & -2.02 & -0.66 & -0.91 & -0.78 & 0.01 & -3.59 & -3.05 \\
\hline & -1.21 & -1.77 & -4.08 & -6.66 & -3.50 & -4.02 & -2.05 & -2.39 & -2.17 & 0.02 & -1.25 & -1.42 \\
\hline
\end{tabular}

Panel B: 10 size (ME) sorted portfolios

\begin{tabular}{|c|c|c|c|c|c|c|c|c|c|c|c|c|}
\hline & small & 2 & 3 & 4 & 5 & 6 & 7 & 8 & 9 & big & $(1-10)$ & $\begin{array}{l}(1,2,3)- \\
(8,9,10)\end{array}$ \\
\hline \multirow[t]{2}{*}{$N=5$} & 1.07 & 0.19 & -0.53 & 0.25 & -0.45 & 0.38 & 0.24 & -0.71 & -1.05 & -0.64 & 1.70 & 1.04 \\
\hline & 0.54 & 0.15 & -0.35 & 0.15 & -0.28 & 0.21 & 0.16 & -0.68 & -1.13 & -0.82 & 1.10 & 1.27 \\
\hline \multirow[t]{2}{*}{$\mathbf{N}=7$} & 3.16 & 0.96 & 0.24 & 0.67 & 0.27 & 0.73 & 0.91 & -0.37 & -0.76 & -0.85 & 4.01 & 2.11 \\
\hline & 1.18 & 0.52 & 0.12 & 0.32 & 0.14 & 0.36 & 0.55 & -0.34 & -0.87 & -1.25 & 1.95 & 1.56 \\
\hline \multirow[t]{2}{*}{$\mathrm{N}=10$} & 4.82 & 1.48 & 2.66 & 2.85 & 2.03 & 1.97 & 1.57 & -0.17 & -0.47 & -1.41 & 6.23 & 3.67 \\
\hline & 1.22 & 0.58 & 0.85 & 1.14 & 0.95 & 1.23 & 0.94 & -0.17 & -0.71 & -4.63 & 1.60 & 1.38 \\
\hline \multirow[t]{2}{*}{$\mathrm{N}=12$} & 5.07 & 2.82 & 3.21 & 3.69 & 3.27 & 2.74 & 2.02 & 0.04 & -0.04 & -1.60 & 6.68 & 4.23 \\
\hline & 1.10 & 0.84 & 0.96 & 1.37 & 1.52 & 1.77 & 1.21 & 0.05 & -0.07 & -3.29 & 1.35 & 1.24 \\
\hline
\end{tabular}




\section{Table 5: Cross sectional regressions}

Results of cross-sectional regressions of expected returns on the 20 portfolios on cash flow duration and covariance measures are presented in Panel A. The coefficient estimates are obtained from OLS regressions. However, the robust t-values are computed using GMM standard errors which account for both cross-sectional and time-series error correlations with Newey-West formula of 7 leads and lags. The one-stage GMM estimation is carried out by stacking moment conditions of both time-series regressions and cross-sectional regressions. For comparison, I also run the standard Fama-MacBeth regressions and report the associated (FM) t-values.

Results of cross-sectional regressions of alternative models are presented in Panel B as benchmarks. I report both Fama-MacBeth t-values and Shanken's t-values which account for errors in the estimates of factor loadings.

Finally, both R-squares and adjusted R-squares of the regressions are reported. Sampling period is from 1964-1995.

Panel A: Cross-sectional regression using cash flow risk measures

\begin{tabular}{ccccc}
\hline & intercept & Cov & Dur x Cov & R-square \\
\cline { 2 - 5 } One factor: & & & & \\
Coefficient & 0.099 & 0.020 & & 0.642 \\
FM t-value & 2.38 & 2.90 & & 0.622 \\
Robust t-value & 2.22 & 1.97 & & \\
\cline { 2 - 5 } & & & & \\
Two Factors: & & & & \\
Coefficient & 0.088 & 0.034 & -0.020 & 0.824 \\
FM t-value & 2.28 & 2.78 & -2.06 & 0.804 \\
Robust t-value & 1.96 & 1.95 & -2.03 & \\
\hline
\end{tabular}

Panel B: Cross-sectional regression of alternative models

\begin{tabular}{lcccccc}
\hline & intercept & $\Delta c$ & $M K T$ & $S M B$ & $H M L$ & R-square \\
\cline { 2 - 6 } CAPM: & \multicolumn{7}{c}{0.117} & & & 0.472 \\
Coefficient & -0.051 & & 1.60 & & & 0.472 \\
FM t-value & -0.78 & & 1.25 & & & \\
Shanken's t-value & -0.65 & & & & 0.518 \\
& & & & & 0.518 \\
CCAPM: & & & & & \\
Coefficient & 0.009 & 0.020 & & & & \\
FM t-value & 0.26 & 2.25 & & & & \\
Shanken's t-value & 0.16 & 1.34 & & & & \\
& & & & & & \\
FF three factors: & & & -0.014 & 0.039 & 0.049 & 0.727 \\
Coefficient & 0.072 & & -0.21 & 1.57 & 1.73 & 0.695 \\
FM t-value & 1.35 & & -0.18 & 1.09 & 1.19 & \\
Shanken's t-value & 1.22 & & & & & \\
\end{tabular}




\section{Table 6: Two-factor cash flow model with "ex-ante” duration measure}

At each year from 1965 to 1999 , I compute $\sum_{t}^{e}$ for each of the 20 portfolios and regress $\sum_{t}^{e}$ on a set of instruments in a panel data setting:

$$
\overline{\sum_{t}^{e}}=\beta \bar{X}+u \text {, where } X=\left[e_{t}, D I V_{t}, S G_{t}\right]
$$

$e$ is the $\log (1+\mathrm{ROE}) ; D I V$ is the $\log$ current book dividend yield ; $S G$ is the sales growth. Variables with upper bars are cross-sectionally de-meaned so there is no constant term in the regression. The robust $t$ value is computed in a GMM system using with Newey-West formula of 7 leads and lags. Details are contained in Appendix A4.2. The results of the panel regression are provided in Panel A.

Given the estimate of $\widehat{\sum_{t}^{e}}$, an "ex-ante" duration measure can be defined as:

$$
\widehat{\operatorname{Dur}}_{t}=\widehat{\sum_{t}^{e}}-\gamma_{t}-\frac{\kappa-\mu_{c}}{1-\rho}
$$

I report the average sample values of $[e, D I V, S G]$ and the average sample estimate of $\widehat{D u r}_{t}$ for each of the 20 portfolios in Panel B.

Finally, I repeat the cross-sectional regression of the two-factor cash flow with the "exante" duration measure $\widehat{D u r}$ and the results are reported in Panel C.

Panel A: Panel regression results

\begin{tabular}{ccccccccccccc}
\hline & \multicolumn{4}{c}{ Full Sample } & \multicolumn{1}{c}{$1965-1982$} & \multicolumn{4}{c}{$1983-1999$} \\
\cline { 2 - 12 } & $e$ & $D I V$ & $S G$ & $R^{2}$ & $e$ & $D I V$ & $S G$ & $R^{2}$ & $e$ & $D I V$ & $S G$ & $R^{2}$ \\
\hline$\beta$ & 5.775 & 21.056 & 0.772 & 0.803 & 3.740 & 18.386 & 0.301 & 0.726 & 6.825 & 18.754 & 2.948 & 0.847 \\
$\mathrm{t}$ & 11.84 & 20.84 & 3.81 & 0.803 & 6.81 & 12.79 & 1.96 & 0.725 & 9.81 & 13.73 & 6.61 & 0.846 \\
robust t & 6.11 & 9.38 & 1.84 & & 6.42 & 13.46 & 1.18 & & 5.95 & 6.74 & 5.03 & \\
\hline
\end{tabular}

Panel B: Ex-ante cash flow duration measure

10 book-to-market (BM) sorted portfolios

\begin{tabular}{cccccccccccc}
\hline & growth & 2 & 3 & 4 & 5 & 6 & 7 & 8 & 9 & value \\
\cline { 2 - 11 }$e$ & 0.136 & 0.142 & 0.135 & 0.135 & 0.110 & 0.100 & 0.087 & 0.080 & 0.062 & 0.038 \\
$D I V$ & 0.101 & 0.091 & 0.079 & 0.070 & 0.066 & 0.062 & 0.056 & 0.049 & 0.045 & 0.032 \\
$S G$ & 0.271 & 0.249 & 0.220 & 0.203 & 0.175 & 0.148 & 0.128 & 0.122 & 0.100 & 0.065 \\
$\widehat{D u r}$ & 1.163 & 1.060 & 0.856 & 0.758 & 0.564 & 0.483 & 0.351 & 0.306 & 0.218 & 0.142 \\
\hline
\end{tabular}

10 size (ME) sorted portfolios

\begin{tabular}{ccccccccccc}
\hline & small & 2 & 3 & 4 & 5 & 6 & 7 & 8 & 9 & big \\
\cline { 2 - 10 } & -0.023 & -0.011 & 0.004 & 0.013 & 0.033 & 0.049 & 0.069 & 0.086 & 0.102 & 0.126 \\
$D I V$ & 0.019 & 0.023 & 0.024 & 0.028 & 0.031 & 0.035 & 0.038 & 0.043 & 0.048 & 0.071 \\
$\widehat{S G}$ & -0.008 & 0.071 & 0.127 & 0.156 & 0.182 & 0.207 & 0.230 & 0.253 & 0.234 & 0.206 \\
$\widehat{D u r}$ & -0.006 & -0.018 & 0.070 & 0.062 & 0.158 & 0.229 & 0.343 & 0.429 & 0.498 & 0.711 \\
\hline
\end{tabular}


Panel C: Two-factor cash flow model with ex-ante cash flow duration measure

\begin{tabular}{ccccc}
\hline & intercept & Cov & $\widehat{\operatorname{Dur}} \times$ Cov & R-square \\
\cline { 2 - 5 } Coefficient & 0.087 & 0.040 & -0.027 & 0.818 \\
FM t-value & 2.27 & 2.62 & -2.00 & 0.797 \\
Robust t-value & 1.94 & 1.91 & -1.87 & \\
\hline
\end{tabular}




\section{Table 7: Diagnostic cross-sectional regressions}

I report results on additional cross-sectional regressions using Fama-MacBeth methodology. The regression in Panel A replaces Dur x Cov by Dur. The regression in Panel B replaces Dur x Cov by $D / P \times C o v$.

I also include characteristics of the 20 portfolios in the regressions. $\log (\mathrm{ME})$ denotes the $\log$ of market value of equity and $\log (\mathrm{BM})$ denotes the $\log$ of book-to-market ratio. Both R-squares and adjusted R-squares of the regressions are reported. Panel $C$ reports the results for the two factor cash flow model and Panel D reports results of the Fama-French three factor model. Sampling period is from 1964-1995.

Panel A: Duration alone as the second factor

\begin{tabular}{lcccc}
\hline & intercept & Cov & Dur & R-square \\
\cline { 2 - 5 } Coefficient & 0.111 & 0.010 & -0.044 & 0.658 \\
FM t-value & 2.47 & 2.49 & -1.46 & 0.618 \\
\hline
\end{tabular}

Panel B: Dividend yield as alternative duration measure

\begin{tabular}{ccccc}
\multicolumn{6}{l}{ Panel B: Dividend yield as alternative duration measure } \\
& intercept & Cov & D/P x Cov & R-square \\
\cline { 2 - 5 } Coefficient & 0.099 & 0.026 & -0.220 & 0.647 \\
FM t-value & 2.38 & 2.73 & -1.13 & 0.606 \\
\hline
\end{tabular}

Panel C: Two factor cash flow model with portfolio characteristic

\begin{tabular}{lcccccc}
\multicolumn{7}{l}{ Panel C: Two factor cash flow model with portfolio characteristic } \\
\hline & Intercept & Cov & Dur $x$ Cov & Log(ME) & Log(BM) & R-square \\
\cline { 2 - 7 } Coefficient & 0.131 & 0.024 & -0.015 & -0.008 & & 0.867 \\
FM t-value & 1.51 & 3.81 & -2.19 & -0.78 & & 0.842 \\
Coefficient & 0.091 & 0.031 & -0.022 & & 0.016 & 0.831 \\
FM t-value & 2.56 & 1.93 & -2.98 & & 0.49 & 0.799 \\
\hline
\end{tabular}

Panel D: FF 3 factor model with portfolio characteristic

\begin{tabular}{lccccccc} 
& Intercept & MKT & SMB & HML & $\log (\mathrm{ME})$ & $\log (\mathrm{BM})$ & R-square \\
\cline { 2 - 7 } Coefficient & 0.128 & -0.012 & 0.028 & 0.035 & -0.009 & & 0.733 \\
FM t-value & 1.78 & -0.20 & 0.94 & 1.42 & -1.85 & & 0.701 \\
Coefficient & 0.062 & 0.050 & 0.021 & -0.091 & & 0.097 & 0.783 \\
FM t-value & 1.17 & 0.80 & 0.74 & -2.24 & & 4.27 & 0.758 \\
\hline
\end{tabular}

Panel E: FF 3 factor model v.s. Two factor Cash flow model

\begin{tabular}{lccccccc}
\hline & Intercept & MKT & SMB & HML & Cov & Dur x Cov & R-square \\
\cline { 2 - 8 } Coefficient & 0.082 & -0.016 & 0.024 & 0.036 & 0.023 & -0.020 & 0.876 \\
FM t-value & 1.49 & -0.25 & 0.81 & 1.33 & 4.85 & -3.06 & 0.831 \\
\hline
\end{tabular}




\section{Table 8: Book-to-market / size double sorted portfolios results}

I repeat the estimations and asset pricing tests for 9 book-to-market / size doubled sorted portfolios. Panel A reports the descriptive statistics and the point estimates of Cov \& Dur of the nine portfolios. Panel B reports Fama-MacBeth cross-sectional regression results of the two factor cash flow model using all nine portfolios and the regression results when the small growth portfolio is excluded. Sampling period is from 1964-1995.

Panel A: Characteristics of the portfolios

\begin{tabular}{|c|c|c|c|c|c|c|}
\hline \multirow[b]{3}{*}{ small } & \multicolumn{3}{|c|}{ Annual execess return } & & & \\
\hline & growth & & value & & & \\
\hline & 0.062 & 0.131 & 0.196 & & & \\
\hline \multirow{4}{*}{ big } & 0.042 & 0.109 & 0.141 & & & \\
\hline & 0.046 & 0.065 & 0.100 & & & \\
\hline & \multicolumn{3}{|c|}{ Book-to-market } & \multicolumn{3}{|c|}{ Size (million \$) } \\
\hline & growth & & value & growth & & value \\
\hline \multirow[t]{2}{*}{ small } & 0.289 & 0.709 & 1.491 & 25.13 & 18.04 & 8.17 \\
\hline & 0.296 & 0.700 & 1.403 & 166.11 & 111.05 & 37.87 \\
\hline \multirow[t]{3}{*}{ big } & 0.295 & 0.684 & 1.299 & 4678.29 & 2066.64 & 836.14 \\
\hline & & Cov & & & Dur & \\
\hline & growth & & value & growth & & value \\
\hline \multirow[t]{2}{*}{ small } & 3.89 & 1.02 & 2.90 & -0.46 & 0.19 & 0.24 \\
\hline & -0.30 & 0.63 & 0.98 & 0.40 & 0.47 & 0.13 \\
\hline big & -2.33 & -0.04 & 1.07 & 1.15 & 0.42 & 0.03 \\
\hline
\end{tabular}

Panel B: Regression results of the two factor cash flow model All nine portfolios:

\begin{tabular}{ccccc}
\hline & intercept & Cov & Dur $x$ Cov & R-square \\
\hline Coefficient & 0.101 & 0.009 & 0.026 & 0.525 \\
FM t-value & 2.35 & 1.18 & 4.93 & 0.366 \\
\hline
\end{tabular}

Excluding the small growth portfolios:

\begin{tabular}{ccccc}
\hline & intercept & Cov & Dur $x$ Cov & R-square \\
\cline { 2 - 5 } Coefficient & 0.071 & 0.053 & -0.036 & 0.896 \\
FM t-value & 1.60 & 5.33 & -3.60 & 0.855 \\
\hline
\end{tabular}




\section{Table 9: Duration and BM sorted portfolios}

At each year from 1975 to 1996, I sort all stocks first into 3 groups according to a rolling-window "ex-ante" cash flow duration measure, and within each group, I further sort stocks into 3 subgroups according to their book-to-market ratio. The book-to-market-ratio, annual excess returns, point estimates of cash flow duration and covariance are reported in the table.

\begin{tabular}{|c|c|c|c|c|c|c|}
\hline & \multicolumn{3}{|c|}{$\mathrm{BM}$} & \multicolumn{3}{|c|}{ Excess Return } \\
\hline & growth & & value & growth & & value \\
\hline Low Dur & 0.502 & 1.063 & 2.269 & 0.063 & 0.077 & 0.123 \\
\hline Med Dur & 0.365 & 0.794 & 1.716 & 0.050 & 0.089 & 0.127 \\
\hline \multirow[t]{3}{*}{ High Dur } & 0.240 & 0.539 & 1.184 & 0.058 & 0.115 & 0.131 \\
\hline & \multicolumn{3}{|c|}{ Dur } & \multicolumn{3}{|c|}{ Cov } \\
\hline & growth & & value & growth & & value \\
\hline Low Dur & 1.28 & 0.22 & -0.05 & -3.83 & -0.43 & 0.65 \\
\hline Med Dur & 0.67 & 0.92 & 0.71 & -0.05 & -0.22 & 4.14 \\
\hline High Dur & 2.41 & 2.77 & 2.76 & -3.52 & -1.30 & 0.18 \\
\hline
\end{tabular}

